\title{
Endogenous Growth with Nominal Frictions
}

\author{
Alfred Maussner \\ Received November 29, 2002; revised version received October 7, 2003
}

\begin{abstract}
This paper analyses monetary business cycles in the framework of a two-sector endogenous growth model with nominal frictions, which stem from overlapping wage contracts. When the accumulation of human capital is considered as home production, it almost insulates the market sector from money supply shocks. Though small, the impulse responses of market output, investment, and paid hours of work are contrary to those observed both in models with exogenous growth and in the data. Both problems are resolved, if the production of human capital is considered a market activity, too. This case also provides a better description of the data than a benchmark model with exogenous growth. The additional channel of intertemporal substitution provided by human capital accumulation does, however, not introduce greater persistence of monetary shocks.
\end{abstract}

Keywords Endogenous Growth, Human Capital Accumulation, Nominal Rigidities, Wage Staggering

JEL Classification E32, E24, F41

Address of Author: Prof. Dr. Alfred Maussner, Department of Economics, University of Augsburg, D-86159 Augsburg, Federal Republic of Germany, alfred.maussner@wiwi.uni-augsburg.de 


\section{Introduction}

The role of money in dynamic general equilibrium (DGE) models is the subject of an intense recent research effort. The majority of papers, e.g., by Chari, Kehoe, and McGrattan (2000), Cho and Cooley (1995), Cooley and Hansen $(1995,1998)$ Christiano, Eichenbaum, and Evans (1997), Hairault and Portier (1995), Maussner (2002), has focused on the short to medium run effects of monetary shocks. Their goal has been to replicate the pattern of impulse responses and second moments that are found in the data. Towards that end a variety of market imperfections have been introduced into the standard neoclassical stochastic growth model to motivate cash holdings and to impose frictions that eliminate the neutrality of money. Common to all these models is that they treat the economy's growth rate as exogenous. Relatively few papers have addressed the role of money in DGE models where the growth rate of output is endogenous. Usually this is accomplished by introducing a second sector whose output is labor augmenting technical progress, as proposed by Lucas (1988) and Uzawa (1965) and extended by Rebelo (1991). Gomme (1993) and Einarsson and Marquis (1999) employed models with this structure to estimate the welfare effects of monetary policy. Both papers motivate money holdings via a cash in advance constraint that binds as long as the nominal rate of interest is positive. The optimal monetary policy, thus, is the Friedman (1969) rule, where deflation at the rate of the real rate of interest reduces the costs of money holdings to zero. Using data on US M1 growth Gomme (1993) finds negligible welfare gains from the switch to the optimal deflation rate. His results are confirmed by Einarsson and Marquis (1999) who use a deterministic version of the endogenous growth model but, in contrast to him, allow labor shares to differ between the two sectors. It is well known that cash in advance constraints imply impulse responses contrary to those observed in empirical studies. For instance, working hours decrease in response to an unexpected increase in the supply of money balances. It is, at least, questionable to discuss welfare issues in models whose short run dynamics is at odds with empirical observations.

There is, thus, a striking contrast between these two strands of research: whereas monetary DGE models with exogenous growth focus on the business cycle effects of monetary policy and employ a variety of market imperfections, DGE models with endogenous growth have been mainly concerned with the welfare implications of monetary

policy within the cash in advance framework. The purpose of this paper is to integrate both approaches and to consider the interaction between the short and the long run effects of monetary policy.

The model of Gomme (1993) minimizes the differences between the output and the human capital producing sector since it assumes equal labor shares and equal rates of depreciation for human and physical capital. Furthermore, human capital production 
is not subject to shocks. I do not impose these restriction so that the real part of my model resembles the stochastic two sector endogenous growth model of Ozlu (1996).

In models with this structure it has been common practice to interpret human capital accumulation as a non-market activity. The market sector produces consumption goods and physical capital. The output of this sector and hours worked in this sector have been used to measure the real effects of monetary policy. I will show that under the usual calibration, the human capital producing sector absorbs most of the effects of monetary shocks. Compared to an exogenous growth model, the effects of monetary policy, therefore, appear to be small. I depart from this interpretation and consider human capital production as a market activity, too. Thus, my measure of output is a weighted average of the production of both sectors and my measure of hours are hours worked in both sectors. Equivalently, aggregate investment is a weighted average of investment in physical and human capital. Under this interpretation money supply shock have important real effects whose size tends to increase with the economy's growth rate. Furthermore, using this approach, the economy's response to an expansive monetary shock is quite in line with empirical wisdom. Thus, this kind of model seems to be a more adequate framework to study the welfare effects of monetary policy than the models used so far.

I assume that real cash holdings are part of the representative household's utility function and parameterize this function so that the cash in advance model is a limiting case if the elasticity of substitution between consumption and real money balances approaches zero. An important consequence is that the link between the growth rates of money and output is not unambiguous as in the cash in advance model but depends upon the size of the intertemporal elasticity of substitution. Furthermore, without any nominal frictions the impact of money on output and employment is small and vanishes in the case of a loglinear parameterization of the household's current period utility function.

I introduce nominal frictions in the form of overlapping wage contracts. In the case of an unexpected monetary shock the aggregate wage rate cannot fully adjust and real wages decline. If the human capital producing sector 2 is more labor intensive than the consumption and capital goods producing sector 1, an assumption usually employed, the relative price of human capital falls and the demand increases. Labor and capital services shift to sector 2. This effect is well known from static two sector models. In addition, there is an intertemporal effect that works through the asset market equilibrium condition: the income effect generated by the increased sector 2 production raises current consumption relative to future consumption, and the household's marginal rate of intertemporal substitution increases, and the higher required return on physical capital reduces investment expenditures. If one considers aggregate variables instead, the impulse responses of the endogenous growth framework resemble those of the exogenous 
growth model.

Hence, if sector 1 variables were used to measure the real effects of monetary shocks, one finds production, investment, and hours to decline. Except for investment, this is the pattern of short run dynamics that would emerge from the cash in advance models of Gomme (1993) and Einarsson and Marquis (1999). This pattern contrasts with empirical findings for the aggregate economy, which show a hump shaped increase in output and hours (see, e.g., Christiano, Eichenbaum, and Evans, (1999)). From the available empirical evidence it is not possible to infer whether the sectoral response in the model is consistent with the facts. Yet, for the present purpose it is also not necessary to know that. My conclusion is just that in order to be consistent with the aggregate facts about the effects of monetary shocks one must use the model's aggregate variables, and not just those of sector 1 .

The increased production of labor augmenting technical progress following an expansionary monetary policy shock does, however, not induce a greater persistence of monetary shocks. The work of Chari, Kehoe, and McGrattan (2000) shows that the lack of persistence in exogenous growth models of the monetary cycle is mainly the result of a sharp increase in investment expenditures that cause prices to rise sharply. In the endogenous growth framework the increased investment in human capital increases the future productivity of labor. This could, in principle, induce workers to increase not only their current but also their future supply of labor, implying a more persistent effect on hours and output. Yet, since investment in physical capital declines, the smaller future stock of capital reduces labor productivity and offsets the incentive to increase future labor supply.

I establish these results in the remainder of the paper in two steps. The next section provides a benchmark model with exogenous growth, money in the utility function and nominal frictions via wage contracts. Section III introduces human capital accumulation into this model and compares its properties with those of the benchmark model. Section IV concludes. ${ }^{1}$

\section{A Benchmark Monetary Model with Exogenous Growth}

\subsection{Wage and Output Determination}

Wage Setting Consider an Economy with a representative household and a representative firm. Time is divided in periods of equals lengths, which are indexed by $t$. The household supplies labor and capital services to the firm, earns wage and rental income, and uses her savings to accumulate cash and physical capital. I introduce wage staggering in this model similar to Cooley and Hansen (1998), although I will

\footnotetext{
${ }^{1}$ An appendix covering technical details and results from additional simulations is available at http://www.wiwi.uni-augsburg.de/vwl/maussner/lehrstuhl/maussner/pap/appendix.pdf.
} 
describe the production structure that underlies their wage equation in more detail. Assume that the household has $n+1$ members who insure themselves against any idiosyncratic risks. Member one supplies labor services $N_{t}^{s}$ on the spot market at the nominal wage $W_{t}^{s}$ per efficiency unit $A_{t} N_{t}^{s}$ of labor. Member $i=1,2, \ldots, n$ enters into a wage contract with the firm. A contract signed $i$ quarters ago is in force until quarter $t+n-i$, specifies a nominal wage (per efficiency unit of labor) $W_{i \tau}^{c}$ for each quarter $\tau=t-i+1, t-i+2, \ldots, t+n-i$ of the contractual period and transfers the right to determine employment $N_{i \tau}^{c}$ to the entrepreneur. Thus, at time $t$ contract $n$ expires and the household member labeled $n$ signs a new contract. The contracting parties agree on a wage $W_{1 t+1}^{c}$ that meets the household's first order conditions with respect to labor supply given her expectations of next period's prices and labor demand. In an expected sense, this wage clears the future labor market for member $n$. This expected market clearing hypothesis dates back to Fischer (1977). Different from his model, I do not assume that the parties negotiate separate wages for each of the subsequent $n$ quarters. Instead, I use the simpler assumption of a cost of living adjustment clause: for quarters $t+2, t+3, \ldots, t+n$ the wage increases according to the average rate of inflation $\pi-1$, which is taken as the rate of inflation along the balanced growth path of the deterministic counterpart of the model. This assumption facilitates the numerical solution of the model considerably and introduces only a modestly larger degree of nominal rigidity than the Fisher (1977) model. ${ }^{2} \quad$ Furthermore, since the model shows almost no persistence in the rate of inflation, even in response to the highly autocorrelated technology shock, this simplification is not at odds with the worker's environment. It is the advantage of the expected market clearing hypothesis that the frictions disappear under perfect foresight. Therefore, the balanced growth path of the model is identically to that of a model without nominal frictions.

As I demonstrate in the Appendix, the adoption of a monopolistically competitive labor market in the sense of Blanchard and Kiyotaki (1987) would boil down to a larger intertemporal elasticity of substitution of leisure, which makes the real variables in both models more sensitive to technology and monetary shocks.

Demand for Labor and Capital Services To implement my model of the labor market I assume that labor $L_{t}$ employed by the representative firm is a Cobb-Douglas

\footnotetext{
${ }^{2}$ Cooley and Hansen (1998) employ the wage equation from a frictionless economy to specify wage contracts. The advantage of my procedure is that wage contracts are endogenous to the model, i.e., their effects are taken into account by the household.
} 
index ${ }^{3}$ labor supplied by the different members of the household:

$$
L_{t}:=(\varphi / n)^{-\varphi}(1-\varphi)^{(\varphi-1)}\left[\prod_{i=1}^{n}\left(N_{i t}^{c}\right)^{\varphi / n}\right]\left(N_{t}^{s}\right)^{(1-\varphi)}, \quad \varphi \in[0,1] .
$$

The firm's production function is

$$
Y_{t}=Z_{t}\left(A_{t} L_{t}\right)^{\alpha} K_{t}^{1-\alpha}, \quad \alpha \in(0,1)
$$

where $Y_{t}, A_{t}$ and $K_{t}$ denote output, labor augmenting technological progress, and capital services, respectively. $Z_{t}$ is a shock to total factor productivity with mean equal to 1 . The deviations from that mean $\hat{z}_{t} \approx \ln \left(Z_{t}\right)$ evolve according to the following $\mathrm{AR}(1)$-process:

$$
\hat{z}_{t}=\rho_{Z} \hat{z}_{t-1}+\epsilon_{t}^{Z}, \quad \epsilon_{t}^{Z} \sim n\left(0, \sigma_{Z}^{2}\right) .
$$

Technical progress grows exogenously at the rate $a-1$ :

$$
A_{t+1}=a A_{t}, \quad a \geq 1
$$

For a given amount of total labor services employed the firm minimizes its wage costs

$$
W_{t} A_{t} L_{t}:=\sum_{i=1}^{n} W_{i t}^{c} A_{t} N_{i t}^{c}+W_{t}^{s} A_{t} N_{t}^{s}
$$

subject to (1) if it employs labor from the different groups according to

$$
\begin{aligned}
N_{i t}^{c} & =\frac{\varphi}{n} \frac{W_{t} L_{t}}{W_{i t}^{c}} \\
N_{t}^{s} & =(1-\varphi) \frac{W_{t} L_{t}}{W_{t}^{s}} \\
W_{t} & =\left[\prod_{i=1}^{n}\left(W_{i t}^{c}\right)^{\varphi / n}\right]\left(W_{t}^{s}\right)^{(1-\varphi)} .
\end{aligned}
$$

Let $P_{t}$ denote the price level and $r_{t}$ the rental rate of capital. Profit maximization with respect to efficient employment $A_{t} L_{t}$ and capital services $K_{t}$ entails the following well know first order conditions:

$$
\begin{aligned}
\frac{W_{t}}{P_{t}} & =\alpha Z_{t}\left(A_{t} L_{t}\right)^{\alpha-1} K_{t}^{1-\alpha}, \\
r_{t} & =(1-\alpha) Z_{t}\left(A_{t} L_{t}\right)^{\alpha} K_{t}^{(1-\alpha)} .
\end{aligned}
$$

\footnotetext{
${ }^{3}$ This is just a convenient simplification. The Appendix shows that the loglinear labor market equilibrium condition is unaffected by this assumption. I could have used more general CES-Indexes instead.
} 


\subsection{Consumption, Labor Supply, and Asset Demand}

Budget Constraint and Preferences The representative household receives wage and rental income as well as governmental transfers $T_{t}$. This income is spent on consumption $C_{t}$ and increased asset holdings. Besides physical capital $K_{t}$, which depreciates at the rate $\delta \in(0,1)$, the household accumulates money $M_{t}$. Thus, in terms of consumption goods, the household's budget constraint is:

$$
\sum_{i=1}^{n} \frac{W_{i t}^{c}}{P_{t}} A_{t} N_{i t}^{c}+\frac{W_{t}^{s}}{P_{t}} A_{t} N_{t}^{s}+r_{t} K_{t}+T_{t} \geq C_{t}+K_{t+1}-(1-\delta) K_{t}+\frac{M_{t+1}-M_{t}}{P_{t}} .
$$

The households seeks decision rules for consumption, labor supply, and investment that maximize her expected lifetime utility:

$$
E_{0}\left\{\sum_{t=0}^{\infty} \beta^{t} u\left(C_{t}, M_{t} / P_{t}, 1-N_{t}\right)\right\}, \quad N_{t}:=\sum_{i=1}^{n} N_{i t}^{c}+N_{t}^{s}, \quad \beta \in(0,1),
$$

where I have normalized total available time per period to 1 so that $1-N_{t}$ is leisure. As Feenstra (1986) demonstrates including real money balances as argument of the period utility function $u(\cdot)$ can be considered as shortcut for a more elaborate model where cash holdings reduce the transactions costs of trade. In the numerical simulations I parameterize the function $u(\cdot)$ as follows:

$$
u\left(C_{t}, M_{t} / P_{t}, 1-N_{t}\right):=\frac{\left[\gamma C_{t}^{\nu}+(1-\gamma)\left(M_{t} / P_{t}\right)^{\nu}\right]^{\frac{1-\eta}{\nu}}\left(1-N_{t}\right)^{\theta(1-\eta)}-1}{1-\eta} .
$$

This function comprises two often considered specific models. If the substitution parameter $\nu$ approaches $-\infty$ the CES-subutility function in (9) reduces to $\min \left\{\gamma C_{t},(1-\right.$ $\left.\gamma)\left(M_{t} / P_{t}\right)\right\}$, which is equivalent to the cash in advance model. The loglinear case derives from (9) for $\nu=0$ and $\eta=1$.

First Order Conditions Let $\Lambda_{t}$ denote the Lagrangean multiplier of the period $t$ budget constraint and let $u_{i}$ denote the partial derivative of $u$ with respect to its $i$-th argument. Then, the first order conditions for maximizing (8) subject to (7) are:

$$
\begin{aligned}
\Lambda_{t} & =u_{1}\left(C_{t}, M_{t} / P_{t}, 1-N_{t}\right) \\
\Lambda_{t} A_{t} \frac{\left(W_{t}^{s}\right)}{P_{t}} & =u_{3}\left(C_{t}, M_{t} / P_{t}, 1-N_{t}\right) \\
0 & =E_{t}\left(\Lambda_{t+1} A_{t+1} \frac{W_{1 t+1}^{c}}{P_{t+1}}-u_{3}\left(C_{t+1}, M_{t+1} / P_{t+1}, 1-N_{t+1}\right)\right), \\
\Lambda_{t} & =\beta E_{t} \Lambda_{t+1}\left(1-\delta+r_{t+1}\right) \\
\Lambda_{t} & =\beta E_{t}\left(\frac{u_{2}\left(C_{t+1}, M_{t+1} / P_{t+1}, 1-N_{t+1}\right)+\Lambda_{t+1}}{P_{t+1} / P_{t}}\right) .
\end{aligned}
$$


(10a) and (10d) taken together imply that in the expected sense the marginal rate of intertemporal substitution $u_{1}\left(C_{t}, \ldots\right) / \beta u_{1}\left(C_{t+1}, ..\right)$ equals the gross return on capital $1-\delta+r_{t+1}$. Labor supply on the spot market is determined by (10a) and (10b), which imply the well known result that the marginal rate of substitution between consumption and leisure must equal the real wage. At time $t$ the contract of household member $n$ needs to be renegotiated. Equation (10c) implies that the wage $W_{1 t+1}^{c}$ is chosen such that in the expected sense the marginal benefits from additional consumption equal the marginal disutility of labor. Using (10a) and (10d) equation (10e) may be written in a more familiar way:

$$
\begin{aligned}
& 0=\beta E_{t} \frac{\Lambda_{t+1}}{P_{t+1} / P_{t}}\left[\frac{u_{2}\left(C_{t+1}, M_{t+1} / P_{t+1}, 1-N_{t+1}\right)}{u_{1}\left(C_{t+1}, M_{t+1} / P_{t+1}, 1-N_{t+1}\right)}-R_{t+1}\right] \\
& \text { where } R_{t+1}=\frac{P_{t+1}}{P_{t}}\left(1-\delta+r_{t+1}\right)-1
\end{aligned}
$$

The term in square brackets is the deviation of the marginal rate of substitution between consumption and real money balances from the costs of cash holdings given by the nominal rate of interest $R$.

\subsection{Money Supply and Dynamics}

Money Supply The government creates new money and distributes it to the household. Thus, transfers $T_{t}$ are given by

$$
T_{t}=\frac{M_{t+1}-M_{t}}{P_{t}}
$$

I use a simple rule for money supply according to which the deviations of the growth factor of money supply $g_{t}:=M_{t+1} / M_{t}$ from its long run mean $g$ obey an AR(1)-process with parameters $\rho_{t}$ and $\sigma_{g}$ :

$$
\hat{g}_{t}=\rho_{g} \hat{g}_{t-1}+\epsilon_{t}^{g}, \quad \epsilon_{t}^{g} \sim n\left(0, \sigma_{g}^{2}\right)
$$

Dynamics The model outlined so far exhibits trend growth. To facilitate its numerical simulation it is convenient to represent its dynamics in terms of variables that are stationary. Given the parameterization of the utility function in equation (9), $u_{1}\left(C_{t}, M_{t} / P_{t}, 1-N_{t}\right)$ as well as $u_{2}\left(C_{t}, M_{t} / P_{t}, 1-N_{t}\right)$ are homogenous of degree $\eta$ in its first two arguments. Therefore, the first order condition (10a) is equivalent to

$$
u_{1}\left(c_{t}, m_{t} / \pi_{t}, 1-N_{t}\right)=\lambda_{t}
$$

where $\lambda_{t}:=\Lambda_{t} A_{t}^{\eta}, c_{t}:=C_{t} / A_{t}, \pi_{t}:=P_{t} / P_{t-1}$ and $m_{t}:=M_{t} /\left(A_{t} P_{t-1}\right)$. The latter definition ensures that $m_{t}$ is a predetermined variable at the beginning of period $t$. For the same reason, I define the contract wage of worker $i$ at beginning of period $t$ 
purchasing power as $w_{i t}^{c}:=W_{i t}^{c} / P_{t-1}$. Combining the definition of the wage index in equation (5c) with (6a) and (10b) and defining $k_{t}:=K_{t} / A_{t}$ gives:

$$
\alpha Z_{t} N_{t}^{\alpha-1} k_{t}^{1-\alpha}=\left(\frac{u_{3}\left(c_{t}, m_{t} / \pi_{t}, 1-N_{t}\right)}{\lambda_{t}}\right)^{1-\varphi} \prod_{i=1}^{n}\left(\frac{w_{i t}^{c}}{\pi_{t}}\right)^{\varphi / n}
$$

The definition of $m_{t}$ and the money supply rule imply the following dynamic equation:

$$
m_{t+1}=\frac{g_{t}}{a \pi_{t}} m_{t}
$$

The economy's resource constraint derives from the household's budget constraint when equations (5a), (5b), (6a), (6b), and (12) are considered. In the stationary variables it is given by:

$$
a k_{t+1}=(1-\delta) k_{t}+Z_{t} N_{t}^{\alpha} k_{t}^{1-\alpha}-c_{t} .
$$

Using (4), the definition $\lambda_{t}:=\Lambda_{t} A_{t}^{\eta}$, and (6a) the Euler equation (10d) changes to

$$
\lambda_{t}=\beta a^{-\eta} E_{t} \lambda_{t+1}\left(1-\delta+(1-\alpha) Z_{t+1} N_{t+1}^{\alpha} k_{t+1}^{-\alpha}\right)
$$

and the Euler equation for money balances yields

$$
\lambda_{t}=\beta a^{-\eta} E_{t}\left(\frac{u_{2}\left(c_{t+1}, m_{t+1} / \pi_{t+1}, 1-N_{t+1}\right)+\lambda_{t+1}}{\pi_{t+1}}\right) .
$$

Since the level of technical progress $A_{t}$ is a deterministic variable, the condition on next period's contract wage (10c) is equivalent to

$$
0=E_{t}\left(\lambda_{t+1} \frac{w_{1 t+1}^{c}}{\pi_{t+1}}-u_{3}\left(c_{t+1}, m_{t+1} / \pi_{t+1}, 1-N_{t+1}\right)\right) .
$$

The nominal wage $W_{1 t+1}^{c}$ implied by this equation replaces the wage labeled $n$ in the wage index of the next period. All other wages increase by steady-state inflation $\pi-1$ :

$$
w_{i+1 t+1}^{c}=\frac{\pi}{\pi_{t}} w_{i t}^{c}, \quad i=1,2, \ldots, n-1,
$$

Figure 1 illustrates the dynamics of the wage structure that derives from these equations.

The system of stochastic difference equations (14) together with the forcing equations (3) and (13) has no analytic solution. There are, however, various approaches to derive numeric approximations to the time paths generated by these equations. ${ }^{4} \mathrm{I}$ follow the procedure proposed by King, Plosser and Rebelo (1988) and also outlined in Burnside (1999), who log-linearize the model at its deterministic steady state and solve the resulting equations along the lines of King and Watson (2002).

\footnotetext{
${ }^{4}$ See Marimon and Scott (1999) for an overview.
} 
Figure 1

Change of Wage Index

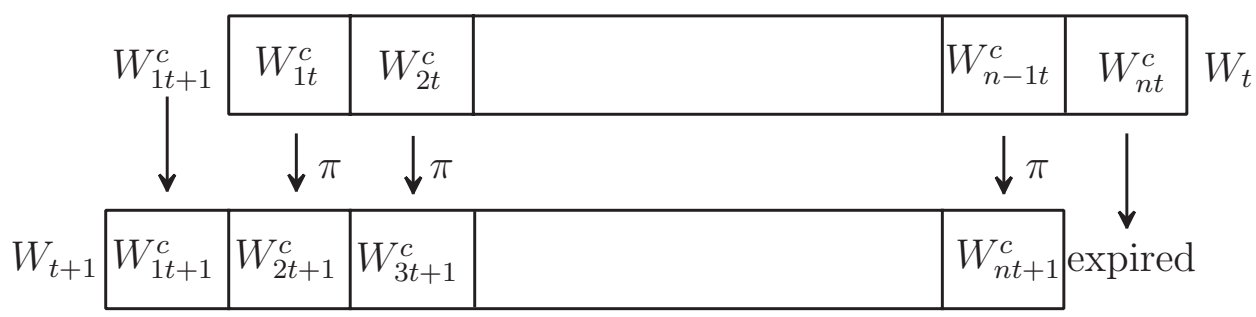

\subsection{Properties of the Benchmark Model}

Calibration My simulations of the model rely on the parameter values given in Table 1. There are two groups of parameters. I picked the values from the first group from the literature. Those of the second group are implied by the model's steady state conditions and West German quarterly time series data from the first quarter of 1975 to the fourth quarter of 1989. This procedure seems more adequate to an aggregate model than the choice of elasticities from micro studies. After all, if the model is taken to mimic certain aspects of the real economy, its long run implications should primarily be consistent with the respective aggregate data and not with microeconomic evidence being subject to aggregation problems. My selection of the sample period rest on the following reasoning: up to the mid seventies the West German average propensity to consume and the average share of investment expenditures show a clear time trend, which is at odds with a long run equilibrium, where both ratios should be constant. To exclude the impact of the German unification in 1990 on the West German economy I did not consider data beyond 1989.

Table 1

Simulation Parameters for the Benchmark Model

\begin{tabular}{|c|c|c|c|}
\hline 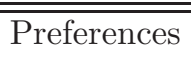 & בProduction & "Wage Setting & "Money Growth \\
\hline$\beta=0.995$ & $\alpha=0.66$ & $n=4$ & $g=1.0171$ \\
\hline$\eta=2.0$ & $a=1.005$ & $\varphi=0.38$ & $\rho_{g}=0$ \\
\hline$\nu=-4.0$ & $\delta=0.011$ & & $\sigma_{g}=0.0172$ \\
\hline$N=0.28$ & $\rho_{Z}=0.92$ & & \\
\hline$\frac{C}{M / P}=0.837$ & $\sigma_{Z}=0.0078$ & & \\
\hline
\end{tabular}

My choice of $\eta=2$ is in the range of values employed in the literature. The main effect of a smaller value of this parameter is to induce greater intertemporal substitution. As a result, the variability of the real variables increases, their autocorrelation coefficients decrease, and the cross correlation of consumption with output becomes smaller (see Table A. 2). 
The parameter $\nu$ is related to the interest elasticity of money demand. Using the parameterization of current period utility in (9) equation (11) implies the following long run relation between real money balances and the nominal interest rate:

$$
\ln (M / P)=\frac{\ln (\gamma /(1-\gamma))}{1-\nu}+\ln C+\frac{1}{\nu-1} \ln R .
$$

Estimates of the German M1 long run interest rate elasticity by Hoffman, Rasche, and Tieslau (1995) average at about -0.2 implying $\nu=-4$. The combination $\eta=1$ and $\nu=0$ implies preferences that are log-linear in consumption, real money balances, and leisure. In this case, the log-linearized model without nominal frictions is immune against monetary shocks (see Table A. 1 in the Appendix).

The remaining parameters in Table 1 are my own estimates from West German data. Since the model excludes the government sector I used data pertaining to the private sector. Thus, $a=1.005$ is the average quarterly growth factor of output, where output is GDP at factor costs net of government consumption. $\alpha=0.66$ is labor's share in output. Labor income is gross wage and salary income of the private sector. My calculation imputes wage earnings to self employed persons equal to the average wage income of private sector employees. I employed the perpetual inventory method to derive a quarterly series of the capital stock from quarterly gross private sector investment expenditures and from the yearly tables of the capital stock. ${ }^{5}$ This procedure also delivers an average rate of depreciation of $\delta=0.011$. My measure of $Z_{t}$ is given by

$$
Z_{t}=\frac{Y_{t}}{\left((1.005)^{t} H_{t}\right)^{0.66} K_{t}^{0.34}},
$$

where $Y_{t}, H_{t}$, and $K_{t}$ are output, are the number of working hours in the private sector and my measure of the quarterly capital stock, respectively. An AR(1) process fitted to the deviations of $Z_{t}$ from its mean provides $\rho_{Z}=0.92$ and $\sigma_{Z}=0.0078$.

The values of the parameters of the utility function are implied from steady state considerations. The value of $\beta$ is consistent with the average productivity of capital of 0.0753 . This requires $\beta=0.995$ and implies an average real rate of interest of $6.2 \%$

\footnotetext{
${ }^{5}$ Let $K_{t+4}$ and $K_{t}$ denote the capital stock at the beginning of two consecutive years, and let $I_{t+i}$ denote gross investment in quarter $t+i, i=0,1,2,3$. The perpetual inventory method,

$$
K_{t+i+1}=(1-\delta) K_{t+i}+I_{t+i}, \quad i=0,1,2,3,
$$

implies the following equation

$$
K_{t+4}=(1-\delta)^{4} K_{t}+\sum_{i=1}^{3}(1-\delta)^{3-i} I_{t+i}
$$

that can be solved for the unknown $\delta$. This solution is employed in (i) to derive estimates of the capital stock in quarter $t+i, i=1,2,3$.
} 
p.a.. ${ }^{6}$ The value of $\theta$ was chosen from the steady state labor market equilibrium condition (14b) to be consistent with $N=0.28$, which is the average share of 1440 hours (16 hours times 90 days) worked per member of the labor force. Together with $\eta=2$ this implies an intertemporal elasticity of substitution with respect to leisure of $1 /(\theta(1-\eta)-1)=-0.33$. This value is much smaller than the often considered value of unity, and, thus, more in line with microeconomic evidence. The effect of a unit elasticity can be seen from Table A. 2 in the Appendix. Given nominal rigidities in the labor market, the smaller value of this parameter induces sufficient real variability.

I used the average velocity of $\mathrm{M} 1$ with respect to consumption, $C /(M 1 / P)=0.837$ to select the value of $\gamma$.

The parameters of the money supply process in (13) were derived from the growth rate of West German M1. Since the estimate of $\rho_{g}$ is not significantly different from zero, I set $\rho_{g}=0$.

In the long run the share of contract workers is equal to $\varphi$ : without expectational errors equations (10b) and (10c) imply that contract workers and spot market workers receive the same wage. In this case equations $(5 \mathrm{a})$ and $(5 \mathrm{~b})$ together with the definition of the labor index $(1)$ imply $N^{s}=(1-\varphi) N$. Therefore, I used the average share of workers that are union members to get $\varphi=0.38$. Cooley and Hansen (1998) chose the size of the contract sector so that their model matches the volatility of hours found in the data. For West German data the value of $\varphi=0.24$ provides this result. The length of the typical German wage contract is one year, which motivates my choice of $n=4$.

Impulse Responses I illustrate the basic working of the model by the impulse responses displayed in Figure 2. Consider a sudden upward jump in the growth rate of money supply in quarter three. Its immediate impact is to increase the household's available income. Since consumption and leisure are normal goods, consumption expenditures rise and labor supply drops. As a consequence, there is a sharp, unexpected increase in the price level which lowers the real wage of contract workers and raises the firm's demand for their labor services. Thus, output and total hours increase. Since the household wants to smooth her consumption stream the extra income generated also increases investment expenditures. The increase of real end of period money balances $M_{t+1} /\left(A_{t+1} P_{t}\right)$ is sensitive to the choice of $\rho_{g}=0$. If the current increase of the money growth rate implies that money growth will be above average in the next periods, too, i.e. if $\rho_{g}>0$, the household expects the future costs of money holdings to rise. As a consequence, she substitutes cash for physical capital. The increased demand for in-

\footnotetext{
${ }^{6}$ This value is about two percentage points above the average ex post real rate of interest on long term bonds. Yet, since capital returns are stochastic in the model, the higher return should be taken to reflect a risk premium. King, Plosser, and Rebelo (1988) use the average return on US stocks of $6.5 \%$ p.a.
} 
Figure 2

Impulse Responses in the Benchmark Model
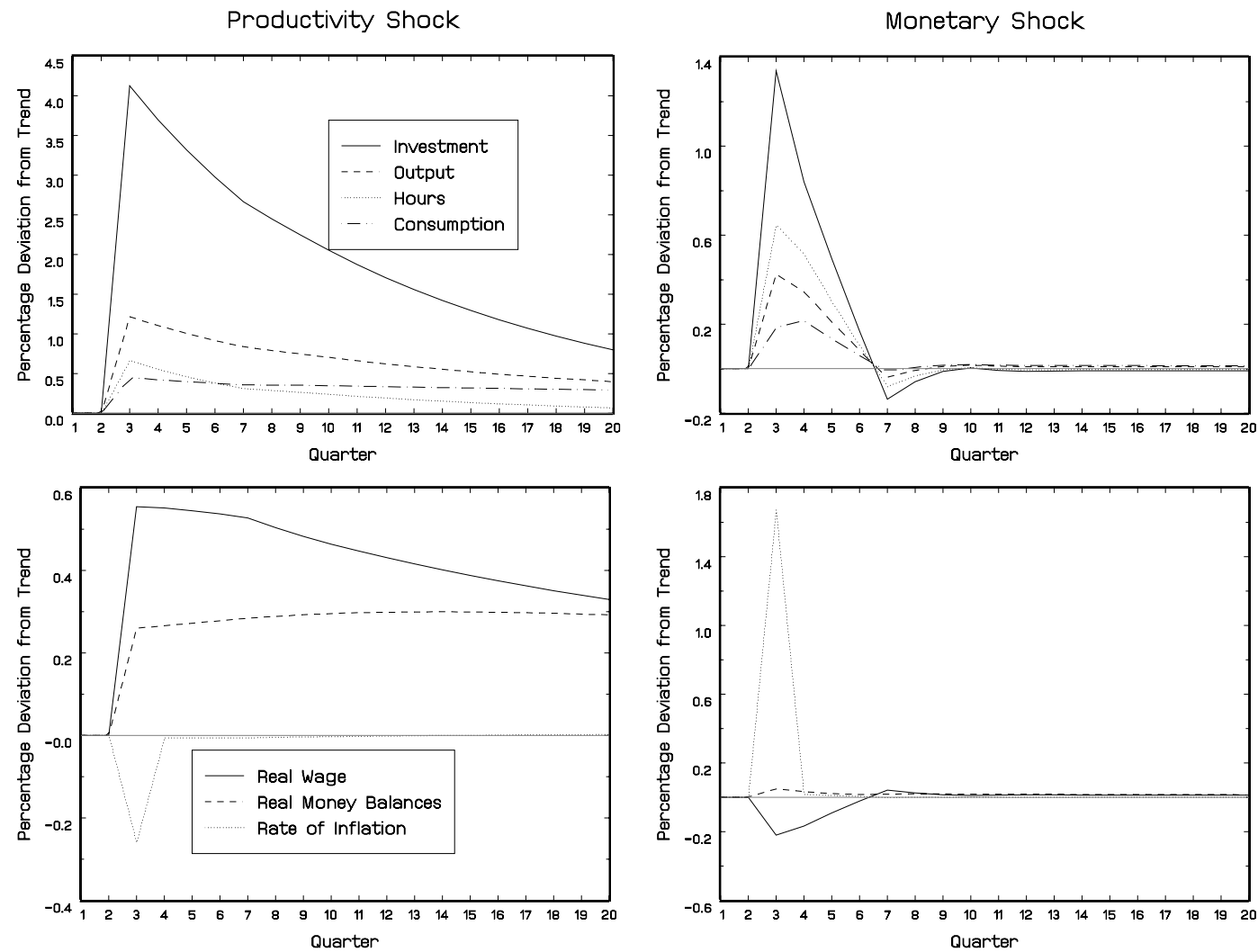

vestment puts additional upward pressure on the price level, which increases by more than the growth rate of money. Thus, real end of period money balances decline in the impact period of the shock.

The US growth rate of M1 is positively autocorrelated with a smaller standard deviation than those found in the German data. The smaller size of innovations offsets the effect of the positive autocorrelation parameter (see Table A. 3 in the Appendix). So the main difference in using German M1 data instead of US M1 data lies in the cross-correlation between real money balances and output. This correlation is close to zero for the US M1 process due to the overshooting of prices as explained above. Since investment and consumption correlate strongly with output, they, too, have a small correlation with real money balances in the US model.

An unexpected outward shift of the production function raises the real wage of all workers. They substitute current leisure against future leisure and supply more hours of labor services. Output increases by more than labor input due to the increased productivity. Thus, in contrast to a monetary driven expansion, average labor productivity is procyclical in a real business cycle. The overall correlation between labor productivity and output, thus, depends upon the relative importance of technology 
Figure 3

Amplification of Productivity Shocks Due to Nominal Rigidities
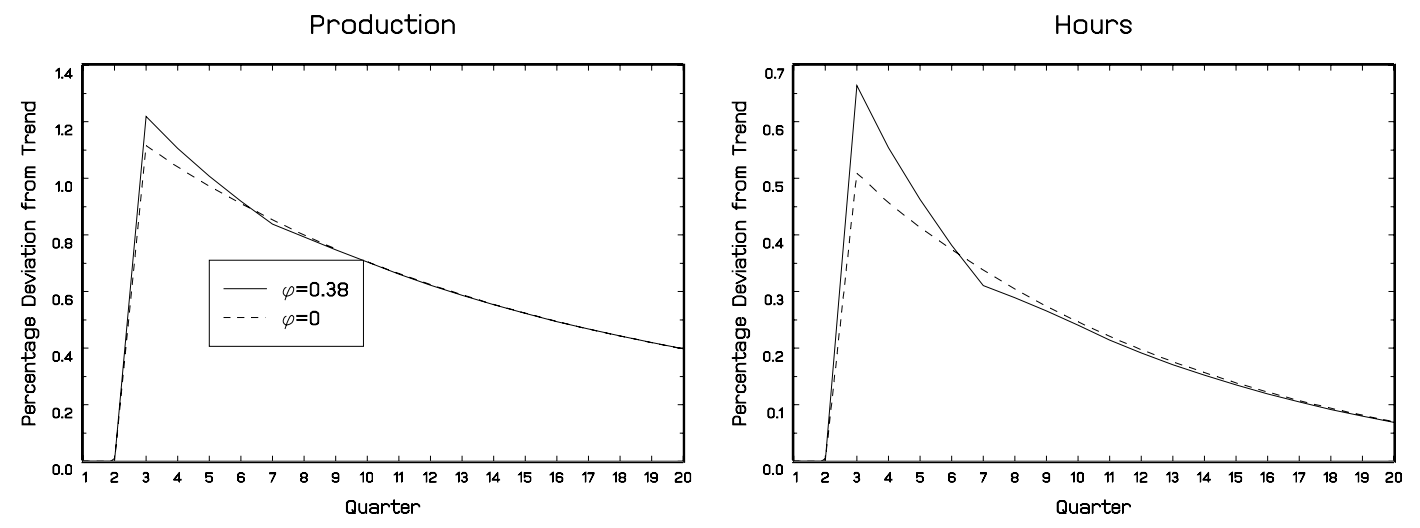

shocks. Note, that despite the high autocorrelation of the productivity shock, the rate of inflation is almost back on its long run path after one period. The nominal rigidity amplifies the impact of supply side shocks, since it dampens the rise of the real wage. Figure (3) illustrates this effect. The dotted lines depict the case $\varphi=0$, where all labor is supplied to the spot market. In the impact period the nominal rigidity amplifies the reaction of output and hours by about 6 and 17.5 percent, respectively.

Time Series Properties Further insights into the properties of the benchmark model provide the second moments of artificial time series computed from simulations of the model. These moments are averages from 500 simulations, where each simulations consists of 60 quarters. Table 2 displays the standard deviation of output, consumption, investment, hours, the real wage, the rate of inflation, and real money balances as well as the cross correlation of these variables with output and real money balances. The respective moments from seasonally adjusted West German data are given in parenthesis. ${ }^{7}$ Both, the moments of the artificial and of the West German data refer to Hodrick-Prescott (HP) filtered time series.

The model is broadly consistent with the empirical facts, although it overstates these. Investment is more and consumption less volatile than output. The autocorrelations

\footnotetext{
${ }^{7}$ As already noted above, my measure of output is GDP net of taxes and subsidies minus government consumption. Consumption refers to household's expenditures on durables and non-durables, except those on residential construction. Investment is firm's fixed investment. Hours are total hours worked in the privat sector, which is total hours minus average hours per worker times the number of public employees. The real wage is gross real compensation of private sector employees per hour. Inflation is the quarterly rate of change of the GDP deflator, and real money balances are M1 divided by the GDP deflator. M1 is from the database of the Deutsche Bundesbank. All other data are from the quarterly national accounts of the German Institute of Economic Research (Deutsches Institut für Wirtschaftsforschung, DIW).
} 
Table 2

Selected Moments from the Exogenous Growth Model

\begin{tabular}{lccccc}
\hline \hline Variable & $s_{x}$ & $s_{x y}$ & $r_{x}$ & $r_{x y}$ & $r_{x m}$ \\
\hline Output & 1.52 & 1.00 & 0.61 & 1.00 & 0.92 \\
& $(1.24)$ & $(1.00)$ & $(0.79)$ & $(1.00)$ & $(0.35)$ \\
Consumption & 0.59 & 0.39 & 0.62 & 0.98 & 0.91 \\
& $(1.10)$ & $(0.88)$ & $(0.82)$ & $(0.66)$ & $(0.57)$ \\
Investment & 5.13 & 3.37 & 0.60 & 1.00 & 0.91 \\
& $(2.54)$ & $(2.04)$ & $(0.81)$ & $(0.81)$ & $(0.44)$ \\
Hours & 1.08 & 0.72 & 0.55 & 0.88 & 0.69 \\
& $(0.84)$ & $(0.68)$ & $(0.42)$ & $(0.30)$ & $(-0.23)$ \\
Real Wage & 0.75 & 0.50 & 0.66 & 0.73 & 0.85 \\
\multirow{3}{*}{ Inflation } & $(1.06)$ & $(0.85)$ & $(0.52)$ & $(0.37)$ & $(0.18)$ \\
& 1.63 & 1.09 & -0.09 & 0.17 & 0.06 \\
Real Money Balances & $(0.28)$ & $(0.23)$ & $(-0.03)$ & $(0.13)$ & $(-0.19)$ \\
& $(2.58)$ & 0.22 & 0.67 & 0.92 & 1.00 \\
& & & & & \\
\hline
\end{tabular}

\footnotetext{
Notes:

$s_{x}:=$ Standard deviation of variable $x, s_{x y}:=$ standard deviation of variable $x$ relative to the standard deviation of output, $r_{x}:=$ first order autocorrelation of variable $x, r_{x y}:=$ first order cross correlation of variable $x$ with output, $r_{x m}:=$ first order cross correlation of variable $x$ with real money balances;

Simulated moments are averages of 500 simulations of HP-filtered series with 60 observations each.

Empirical values from HP-filtered data from 75.i to 89.iv in parentheses.
}

of all variables are not far off their empirical counterparts. The cross correlations with output have the correct signs though they are exaggerated for all variables except inflation. Inflation is a great deal more volatile, and, thus, real money balances are much smoother than empirically observed.

Table 3 uncovers the contribution of monetary policy to the business cycle. It compares the standard deviations from Table 2 to those implied by a policy of constant money growth. Whereas output, consumption, and investment are less sensitive to monetary policy - their respective standard deviations shrink by 6, 11, and 4.4 percent - there is a remarkable reduction in the variability of hours of about 30 percent.

\section{Endogenous Growth}

It requires only a few steps to explain the level of labor augmenting technical progress within the basic setting of the model from the previous section. These steps are presented in the next subsection. 
Table 3

Stable Money Growth in the Exogenous Growth Model

\begin{tabular}{|c|c|c|c|}
\hline \multirow[t]{2}{*}{ Variable } & \multicolumn{2}{|l|}{$s_{x}$} & \multirow[t]{2}{*}{$\Delta s_{x}$} \\
\hline & $\sigma_{g}=1.0172$ & $\sigma_{g}=0$ & \\
\hline Output & 1.52 & 1.43 & -6.07 \\
\hline Consumption & 0.59 & 0.52 & -11.16 \\
\hline Investment & 5.13 & 4.90 & -4.50 \\
\hline Hours & 1.08 & 0.75 & -30.86 \\
\hline Real Wage & 0.75 & 0.70 & -6.33 \\
\hline Inflation & 1.63 & 0.25 & -84.84 \\
\hline Real Money Balances & 0.33 & 0.32 & -1.11 \\
\hline
\end{tabular}

\subsection{The Model}

Human Capital Accumulation In addition to money and physical capital the level of technical progress $A_{t}$ is now considered an additional asset that the household can accumulate. As explained in the introduction, I assume that knowledge is produced by a second market sector and sold to the household at the relative price $q_{t}$. Knowledge capital depreciates at a given rate $\delta_{A}$ so that

$$
A_{t+1}-\left(1-\delta_{A}\right) A_{t}
$$

is the new knowledge acquired in period $t$. The budget constraint in equation (7) is then extended to:

$$
\begin{aligned}
& \sum_{i=1}^{n} \frac{W_{i t}^{c}}{P_{t}} A_{t} N_{i t}^{c}+\frac{W_{t}^{s}}{P_{t}} A_{t} N_{t}^{s}+r_{t} K_{t}+T_{t} \\
& \geq C_{t}+K_{t+1}-\left(1-\delta_{K}\right) K_{t}+\frac{M_{t+1}-M_{t}}{P_{t}}+q_{t}\left(A_{t+1}-\left(1-\delta_{A}\right) A_{t}\right),
\end{aligned}
$$

where now $\delta_{K}$ denotes the rate of depreciation of physical capital. The household maximizes (8) subject to (16). The first order conditions for this program are those presented in (10) and an additional Euler equation that governs knowledge investment:

$$
q_{t} \Lambda_{t}=\beta E_{t} \Lambda_{t+1}\left[\sum_{i=1}^{n} \frac{W_{i t_{1}}^{c}}{P_{t+1}} N_{i t+1}^{c}+\frac{W_{t+1}^{s}}{P_{t+1}} N_{t+1}^{s}+q_{t+1}\left(1-\delta_{A}\right)\right] .
$$

The Supply Side There are two sectors of production. Sector 1 produces consumption goods. In addition, its output is used to accumulate physical capital. I continue to denote this sector's output by $Y_{t}$. The output of sector 2 is new knowledge as defined in equation (15). Both sectors employ labor and physical capital and produce according 
to a constant returns to scale Cobb-Douglas functions. I denote the share of labor and capital employed in sector 1 by $u_{t}$ and $v_{t}$ respectively. Raw labor $L_{t}$ is still given by the index defined in equation (1). Thus, the production of sector 1 is given by

$$
Y_{t}=Z_{Y t}\left(u_{t} A_{t} L_{t}\right)^{\alpha}\left(v_{t} K_{t}\right)^{1-\alpha}, \quad \alpha \in(0,1)
$$

and that of sector 2 by

$$
A_{t+1}-\left(1-\delta_{A}\right) A_{t}=Z_{A t}\left[\left(1-u_{t}\right) A_{t} L_{t}\right]^{\zeta}\left[\left(1-v_{t}\right) K_{t}\right]^{1-\zeta}, \quad \zeta \in(0,1) .
$$

The variables $Z_{Y t}$ and $Z_{A t}$ represent stochastic shifts of the respective sector's total factor productivity. The deviations of these variables from their respective means $Z_{Y}$ and $Z_{A}$ evolve according to the following $\mathrm{AR}(1)$-processes:

$$
\hat{z}_{j t}=\rho_{j} \hat{z}_{j t-1}+\hat{\epsilon}_{j t}, \quad \epsilon_{j t} \sim n\left(0, \sigma_{j}^{s}\right), \quad j \in\{Y, A\}
$$

Both sectors minimize their respective wage bill so that aggregate demand for the various segments of the labor market is still given by equations (5). In a second step, sector 1 maximizes

$$
Y_{t}-\left(W_{t} / P_{t}\right) u_{t} A_{t} L_{t}-r_{t} v_{t} K_{t}
$$

subject to (18), and sector 2 solves

$$
\max \quad q_{t}\left(A_{t+1}-\left(1-\delta_{A}\right) A_{t}\right)-\left(W_{t} / P_{t}\right)\left(1-u_{t}\right) A_{t} L_{t}-r_{t}\left(1-v_{t}\right) K_{t}
$$

subject to (19). The respective first order conditions imply the following efficiency conditions, which I state in the stationary variables introduced above:

$$
\begin{aligned}
\frac{W_{t}}{P_{t}} & =\alpha Z_{Y t}\left(u_{t} L_{t}\right)^{\alpha-1}\left(v_{t} k_{t}\right)^{1-\alpha}, \\
r_{t} & =(1-\alpha) Z_{Y t}\left(u_{t} L_{t}\right)^{\alpha}\left(v_{t} k_{t}\right)^{-\alpha}, \\
q_{t} & =\frac{\alpha Z_{Y t}\left(u_{t} L_{t}\right)^{\alpha-1}\left(v_{t} k_{t}\right)^{1-\alpha}}{\zeta Z_{A t}\left[\left(1-u_{t}\right) L_{t}\right]^{\zeta-1}\left[\left(1-v_{t}\right) k_{t}\right]^{1-\zeta}}, \\
\frac{v_{t}}{1-v_{t}} & =\frac{1-\alpha}{\alpha} \frac{\zeta}{1-\zeta} \frac{u_{t}}{1-u_{t}} .
\end{aligned}
$$

These equations determine the allocation of labor and capital services between the two sectors. Together with the household's first order conditions they induce a system of stochastic difference equations in stationary variables. I reproduce this system as well as its log-linear approximation around a deterministic balanced growth path in the Appendix, since this is mainly a technical issue that does not add much to the intuition behind the model. 


\subsection{Properties of the Model}

Calibration There are, in principal, two alternative interpretations of the endogenous growth model. The business cycle literature has focused on the home work interpretation of human capital accumulation (Ozlu (1996), Gomme (1993), Einarsson and Marquis (1997), (1998), Benhabib Et Al. (1991)) whereas my exposition of the model emphasized human capital production as a market activity. This difference has considerable consequences for the calibration procedure. ${ }^{8}$

There are some parameters from the benchmark model that have the same interpretation in the endogenous growth framework. I either keep their values or pin them down as explained above. These parameters are $\beta, \eta, \delta_{K}, \nu, \gamma, \varphi$, and $n$.

Estimates of the half life of knowledge found in Giarini and Liedtke (1998), p. 104, provide a guideline to choose the value of $\delta_{A}$. Basic knowledge has a half life of 20 years, academic knowledge of 10 years, and knowledge specific to professional engineers of only three years. Thus, 20 years appears to be a baseline value, and I set $\delta_{A}=0.009$.

Unfortunately, there is no straight forward approach to assign conclusive values to the parameters of the sector 2 production function. Moreover the usual procedure to derive the properties of the technology shock of sector 1 from the properties of the Solow residual is not valid. Aggregate output (scaled by the level of technological progress) in terms of sector 1 goods is

$$
x_{t}:=y_{t}+q_{t}\left(a_{t}+\delta_{A}-1\right) .
$$

Thus, it is impossible to infer $Z_{Y t}$ from GDP, hours, and the capital stock. Since I am not able to provide a solution to this problem, I follow Benhabib Et Al. (1991) and Ozlu (1996) and assign to $\rho_{Y}$ and $\sigma_{Y}$ the same values as in the exogenous growth framework and assume $\rho_{A}=\rho_{Y}$. I choose $\sigma_{A}$ so that aggregate output is as volatile as its empirical counterpart. I normalize the mean of $Z_{Y t}$ to one and determine the mean of $Z_{A t}$ from the observed growth rate of output, as explained in the Appendix.

The choice of $\zeta$ ranges from $\zeta=1$ (cf. Lucas (1988)) to $\zeta=\alpha$ (cf. Gomme (1993)). As Ozlu (1996) I use $\zeta=0.95$. There are no significant differences in the moments of aggregate variables for $\zeta \in[1,0.9]$, as Tables A. 1 and A. 2 in the Appendix show. Smaller values of $\zeta$ increase however the volatility of sectoral variables and reduce their cross correlations with GDP. In the borderline case of $\zeta=\alpha$ there is considerable variability of sectoral variables that also shows up in a markedly increased variability of aggregate variables. The reason for this result can be seen from equation (21c) that reduces to $q_{t}=Z_{Y t} / Z_{A t}$. Hence, the variance of the percentage deviation of the relative price of sector 2 output is equal to the sum of the variance of the sector 1 and sector 2 shocks, if these two are uncorrelated. Plausible results require smaller values of both

\footnotetext{
${ }^{8}$ The more formal details of the calibration procedure are discussed in the Appendix.
} 
the variance of the sector 1 and sector 2 productivity shock, as can also be seen from the simulation experiments of Gomme (1993). Therefore, I do not consider this case here.

Finally, labor's share in aggregate output of 0.66 can be used to find the value of $\alpha=0.48$, and the value of $\theta$ is derived from the observed value of $N$ using the labor marked equilibrium condition. This implies an even smaller intertemporal elasticity of substitution of leisure of about -0.2 than in the exogenous growth model. Thus, in as far as the model predicts slightly stronger effects of monetary policy on output, these are not due to the household's greater willingness to substitute current against future leisure.

If human capital accumulation is considered as home production, instead, there is no need to recalibrate $\alpha$ and the Solow residual can still be used to derive the properties of the sector 1 shock. The empirical value of $N$ is then identified with $u N$ from the model and used to pin down $\theta$. Table 4 summarizes the various parameter settings for the model's simulation.

Table 4

Simulation Parameters for the Endogenous Growth Model

\begin{tabular}{cllll}
\hline \hline Preferences & Sector 1 & Sector 2 & Wage Setting & Money Growth \\
\hline$\beta=0.995$ & $\alpha=0.48$ & $\zeta=0.95$ & $n=4$ & $g=1.0171$ \\
$\eta=2.0$ & & $a=1.005$ & $\varphi=0.38$ & $\rho_{g}=0$ \\
$\nu=-4.0$ & $\delta_{K}=0.011$ & $\delta_{A}=0.009$ & & $\sigma_{g}=0.0172$ \\
$N=0.28$ & $\rho_{Y}=0.92$ & $\rho_{A}=\rho_{Y}$ & & \\
$\frac{C}{M / P}=0.837$ & $\sigma_{Y}=0.0078$ & $\sigma_{A}=0.94 \sigma_{Y}$ & & \\
\hline
\end{tabular}

The Relation Between Money and Output Growth In the log-linear cash in advance models of Gomme (1993) and Einarsson and Marquis (1998) the relation between the growth rates of money supply and output is unambiguously negativ. This can be seen by looking at the condition that determines the long run supply of labor derived as equation (A.5a) in the Appendix and reproduced here:

$$
\begin{aligned}
\frac{W}{P} & =\frac{u_{3}(c, M /(A P), 1-N)}{u_{1}(c, M /(A P), 1-N)} \Leftrightarrow \alpha Z_{Y}\left(\frac{u N}{v k}\right)^{(\alpha-1)}=\theta \frac{c}{1-N} \Delta(g), \\
\Delta(g) & =1+\frac{1-\gamma}{\gamma}\left(\frac{\gamma}{1-\gamma} \frac{g a^{\eta-1}-\beta}{\beta}\right)^{\nu /(\nu-1)} .
\end{aligned}
$$

The log-linear cash in advance model is equivalent to $\eta=1$ and $\nu /(\nu-1)=1$ so that equation (22) reduces to

$$
\frac{W}{P}=\alpha Z_{Y}\left(\frac{u N}{v k}\right)^{(\alpha-1)}=\theta \frac{c}{1-N} \frac{g}{\beta}
$$


The term $g / \beta$ is the wedge between the marginal rate of substitution between consumption and leisure and the real wage. In the more general case it is given by the function $\Delta(g)$ and depends also on the growth rate of output. In the log-linear cash in advance model a higher growth rate of money supply increases the costs of money holdings and acts as tax on labor earnings, since income earned today can only be spent on consumption tomorrow. Thus, labor supply is reduced. But with less labor supplied the return on human capital is smaller, too, since it depends on $(W / P) N$. Therefore, the household devotes less resources on human capital accumulation and the growth rate of output declines. In the more general case of equation (22) a smaller rate of output growth, however, reduces the wedge between the real wage and the marginal rate of substitution between consumption and leisure, if $\eta$ is smaller than one. If $\eta$ is small enough, this effect reverses the relation between the growth rates of output and money supply. Figure 4 illustrates this finding for two different values of $\eta$. The left panel

Figure 4

The Relation Between the Growth Rates of Output and Money Supply
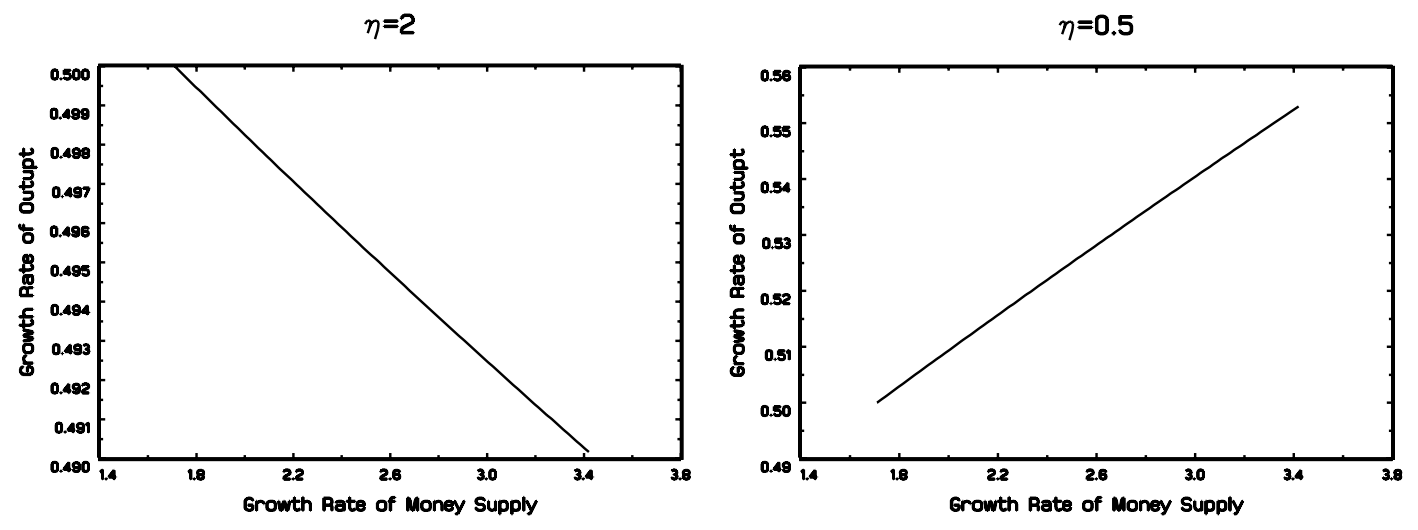

rests on the calibration given in Table 4 . It depicts the growth rate of output $a-1$ as a function of the growth rate of money supply in the interval [1.72, 3.44]. Comparing the end points reveals that a doubling of the growth rate of money supply reduces the growth rate of output by about 0.01 percentage points(two percent of the initial growth rate of 0.5 percent). The plot in the right panel rests on different parameter values, since, ceteris paribus, a smaller value of $\eta$ implies a smaller steady state real rate of interest. Therefore, where necessary, the parameters were adjusted to be consistent with those underlying the graph in the left panel. Given this calibration money has a more severe influence on output growth: raising $g-1$ to twice its empirical value increases the rate of output growth by about 0.05 percentage points (i.e., 10 percent of its initial value). 
Money Supply Shocks Figure 5 displays the economy's reaction to a sudden departure of the money growth rate from its long run level in the size of one standard deviation of $\epsilon_{g t}$. If human capital production is regarded as a non-market activity, the upper left panel gives the answer to what happens to output, investment, and hours. My interpretation of the model is reflected by the impulse responses in the lower left panel. Aggregate output is the weighted average of sector 1 and sector 2 output, and aggregate investment is the weighted average of investment in physical and human capital. For both aggregates the relative price of human capital $q_{t}$ serves as weight. It is obvious from Figure 5 that monetary shocks have quite different consequences in

Figure 5

A Monetary Shock in the Endogenous Growth Model
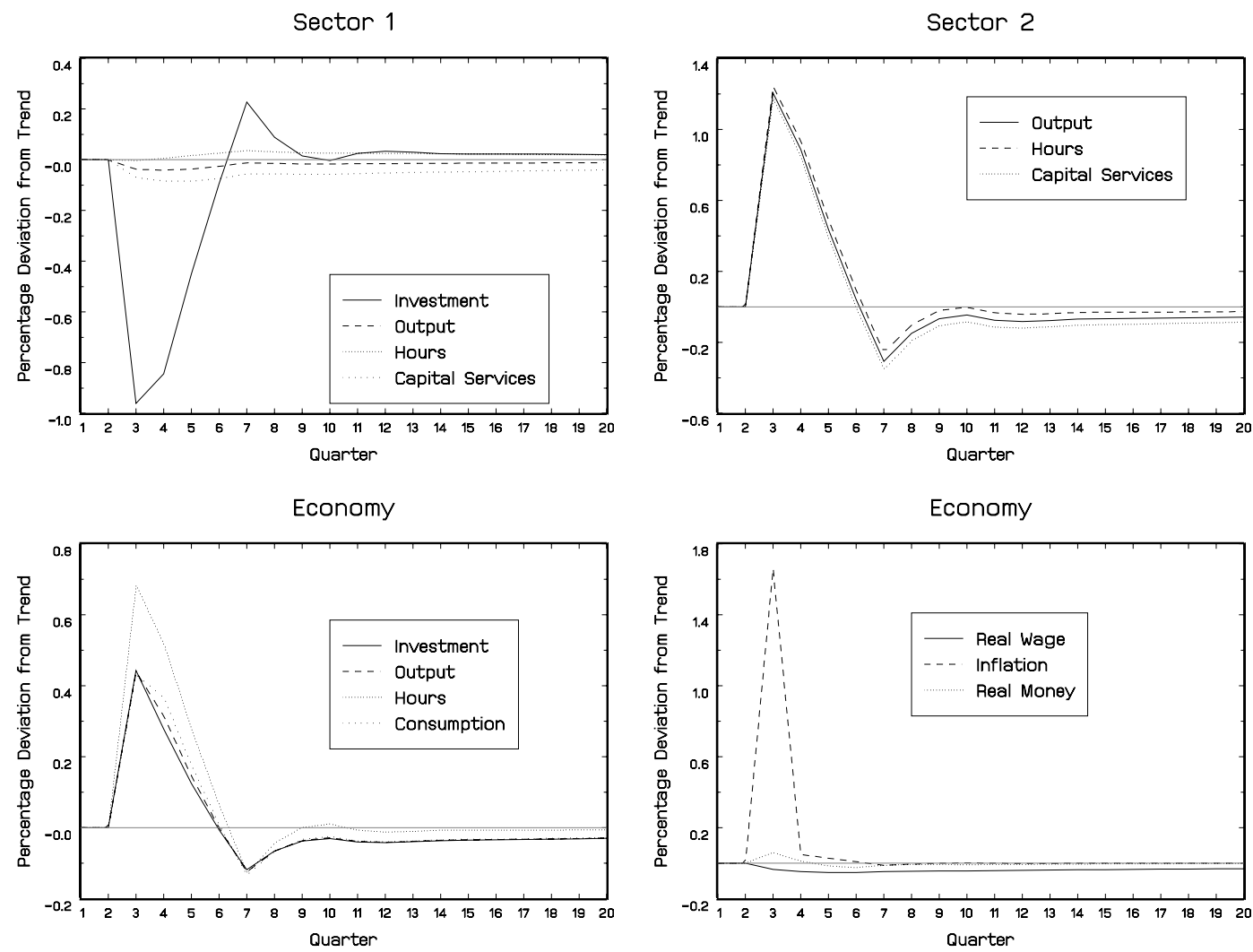

the endogenous growth model as opposed to the exogenous growth framework if in the former sector 1 variables indicate the business cycle. Following the shock in quarter $t=3$ output, investment, and hours decrease, quite in contrast to the results of empirical estimates, ${ }^{9}$ although the departure of output and hours from their trend level is very small. Considering aggregate variables, instead, delivers results similar to those of the benchmark model. Aggregate output, investment, and hours increase, as well as consumption and real money balances.

\footnotetext{
${ }^{9}$ See, e.g., Christiano, Eichenbaum and Evans (1997)
} 
The intuition behind this result is quite simple: As in the benchmark model, a monetary shock has a negative impact on the real wage. Yet, if sector 2 is more labor intensive than sector 1 , the relative price of human capital production declines and resources shift from sector 1 to sector 2 . Investment in physical capital is reduced since the increase in current consumption relative to future consumption raises the required return on physical capital. In the exogenous growth framework this effect is outweighed by the household's desire to smooth consumption, which is accomplished here via increased investment in knowledge.

As in the exogenous growth framework it is the length of the contract period that determines the persistence of the monetary shock. When the last group of workers has been able to adjust its wage most of the shocks impact has disappeared. In the exogenous growth model this result can be traced back to the sharp increase in investment expenditures that boost aggregate demand (see Chari, Kehoe, and McGrattan (2000)). In the endogenous growth model the reasoning is quite different. On the one hand, the household accumulates more human capital so that workers are more productive in the aftermath of a monetary shock. This tends to increase future labor demand and makes the shock more persistent. On the other hand, there is a shortage of physical capital in the periods following the shock. This negative effect on labor demand makes the shock less persistent.

Empirical Fit Selected moments computed from 500 simulations of the model are gathered in Table 5. Compared with the benchmark model the model provides a better description of the data. Focusing on the 23 moments related to consumption, investment, hours, the real wage, inflation, and real money balances, 13 of them are closer to their empirical counterparts, 3 of them have not changed and 7 are farther apart from the empirical moments.

Severeness of Monetary Cycles Table 6 reveals the severeness of monetary cycles. Again, the interpretation of the model is decisive for the answer. When sector 1 variables indicate the cycle, monetary shocks have almost negligible effects: the standard deviations of output and hours do not react to the change in monetary policy and the volatility of physical capital investment shrinks by only 2 percent. This result also holds, if the model is calibrated in the spirit of the home production interpretation of human capital accumulation, as Table A. 3 in the Appendix reveals.

There are, however, sizeable reductions of the standard deviations of GDP, aggregate investment, and consumption, that exceed those in the benchmark model (see Table 3). The noticeable effects of monetary shocks on consumption stem from the interaction between consumption and cash balances and vanish in the case of log-linear preferences (see row 6 of Table A. 7 in the Appendix). 
Table 5

Selected Moments from the Endogenous Growth Modell

\begin{tabular}{lccccc}
\hline \hline Variable & $s_{x}$ & $s_{x y}$ & $r_{x}$ & $r_{x y}$ & $r_{x m}$ \\
\hline GDP & 1.24 & 1.00 & 0.61 & 1.00 & 0.91 \\
& $(1.24)$ & $(1.00)$ & $(0.79)$ & $(1.00)$ & $(0.35)$ \\
Sector 1 Output & 1.98 & 1.62 & 0.64 & 0.24 & 0.19 \\
Sector 2 Output & 3.92 & 3.21 & 0.59 & 0.62 & 0.58 \\
Sector 1 Investment & 6.20 & 5.11 & 0.62 & -0.03 & -0.05 \\
Aggregate Investment & 1.54 & 1.24 & 0.61 & 0.99 & 0.91 \\
& $(2.54)$ & $(2.04)$ & $(0.81)$ & $(0.81)$ & $(0.44)$ \\
Consumption & 0.91 & 0.74 & 0.60 & 0.91 & 0.80 \\
& $(1.10)$ & $(0.88)$ & $(0.82)$ & $(0.66)$ & $(0.57)$ \\
Sector 1 Hours & 2.24 & 1.85 & 0.63 & -0.07 & -0.15 \\
Sector 2 Hours & 3.33 & 2.73 & 0.58 & 0.53 & 0.47 \\
Aggregate Hours & 1.14 & 0.93 & 0.53 & 0.79 & 0.62 \\
& $(0.84)$ & $(0.68)$ & $(0.42)$ & $(0.30)$ & $(-0.23)$ \\
Real Wage & 0.83 & 0.67 & 0.67 & 0.79 & 0.89 \\
& $(1.06)$ & $(0.85)$ & $(0.52)$ & $(0.37)$ & $(0.18)$ \\
Inflation & 1.61 & 1.33 & -0.07 & 0.27 & 0.14 \\
& $(0.28)$ & $(0.23)$ & $(-0.03)$ & $(0.13)$ & $(-0.19)$ \\
Real Money Balances & 0.33 & 0.27 & 0.67 & 0.91 & 1.00 \\
& $(2.58)$ & $(2.08)$ & $(0.80)$ & $(0.35)$ & $(1.00)$ \\
\hline
\end{tabular}

\footnotetext{
Notes:

$s_{x}:=$ Standard deviation of variable $x, s_{x y}:=$ standard deviation of variable $x$ relative to the standard deviation of GDP, $r_{x}:=$ first order autocorrelation of variable $x, r_{x y}:=$ first order cross correlation of variable $x$ with GDP, $r_{x m}:=$ first order cross correlation of variable $x$ with real money balances;

Simulated moments are averages of 500 simulations of HP-filtered series with 60 observations each.

Empirical values from HP-filtered data from 75.i to 89.iv in parentheses.
}

Money supply shocks are about as severe with respect to hours, inflation, and real money balances in the endogenous growth framework as in the benchmark model. Overall, monetary cycles are moderately more pronounced when growth is endogenous.

The three rightmost columns in Table 5 present the results of simulations that assume zero growth. Besides the necessary adjustment of the average total factor productivity of sector $2, Z_{A}$, the other parameters were not changed. Comparing column 4 with column 7 , it appears that monetary shocks are slightly less severe with respect to GDP, aggregate investment, and consumption in the growing economy.

\section{Conclusion}

This paper examines monetary business cycles in an endogenous growth framework. It is an attempt to integrate two strands of research on the role of money in dynamic equilibrium models. On the one hand, there is the abundance of work that has tried to replicate the empirical pattern of impulse responses that characterize monetary cycles within the framework of exogenous growth. On the other hand, there are endogenous 
Table 6

Stable Money Growth in the Endogenous Growth Model

\begin{tabular}{lcrrrrr}
\hline \hline Variable & \multicolumn{3}{c}{$a-1=0.005$} & \multicolumn{3}{c}{$a-1=0$} \\
& $s_{x}$ & & $\Delta s_{x}$ & \multicolumn{2}{c}{$s_{x}$} & $\Delta s_{x}$ \\
& $\sigma_{g}=1.0172$ & $\sigma_{g}=0$ & & $\sigma_{g}=1.0172$ & $\sigma_{g}=0$ \\
\hline GDP & 1.24 & 1.11 & -10.39 & 1.28 & 1.14 & -11.34 \\
Sector 1 Output & 1.98 & 1.98 & -0.04 & 2.18 & 2.17 & -0.06 \\
Sector 2 Output & 3.92 & 3.63 & -7.44 & 3.87 & 3.59 & -7.10 \\
Sector 1 Investment & 6.20 & 6.08 & -1.98 & 6.18 & 6.07 & -1.77 \\
Aggregate Investment & 1.54 & 1.44 & -6.27 & 1.52 & 1.40 & -7.80 \\
Consumption & 0.91 & 0.71 & -22.37 & 0.94 & 0.71 & -23.79 \\
Sector 1 Hours & 2.24 & 2.24 & 0.01 & 2.58 & 2.58 & -0.02 \\
Sector 2 Hours & 3.33 & 2.97 & -10.75 & 3.20 & 2.85 & -10.77 \\
Aggregate Hours & 1.14 & 0.79 & -30.74 & 1.22 & 0.87 & -28.45 \\
Real Wage & 0.83 & 0.82 & -0.22 & 0.85 & 0.85 & -0.07 \\
Inflation & 1.61 & 0.24 & -84.92 & 1.62 & 0.23 & -85.67 \\
Real Money Balances & 0.33 & 0.32 & -2.33 & 0.30 & 0.29 & -2.17 \\
\hline
\end{tabular}

Notes:

$s_{x}:=$ Standard deviation of variable $x, \Delta s_{x}:=$ percentage change of standard deviation of variable $x$ relative to the case of constant money growth.

growth models with cash in advance constraint that estimate the welfare gains of optimal monetary policy. I employ the endogenous growth framework from the latter class of models and study the type of questions posed in the former.

I introduce growth using the two-sector model of Rebelo (1991). Yet, in contrast to previous work, namely by Gomme (1993), I regard human capital production as a market activity. This interpretation is decisive with respect to the severeness and the qualitative properties of monetary cycles. If knowledge production is a solely private activity it almost insulates the market sector from the effects of monetary shocks. Furthermore, the impulse responses of output, investment, consumption, and hours are at odds with the empirical cycle. Both problems are resolved when human capital is produced from a second market sector. In addition, this model provides a better description of the data as a benchmark model with exogenous growth.

The endogenous growth framework, as presented here, does, however, not resolve the much discussed persistence problem: as in the benchmark exogenous growth model the half time of a money supply shock depends upon the length of the wage contract. It requires future research to provide answers to this question within the general framework developed in this paper. 


\section{Acknowledgements}

I am grateful to two anonymous referees for their comments and suggestions. The usual disclaimer applies. 


\section{References}

Benhabib, J., Rogerson, R. and Wright, R. (1991): "Homework in Macroeconomics: Household Production and Aggregate Fluctuations." Journal of Political Economy 99: 1166-1187.

Blanchard, O. J., Kiyotaki, N. (1987): "Monopolistic Competition and the Effects of Aggregate Demand." American Economic Review 77: 647-666.

Burnside, C. (1999): "Real Business Cycle Models: Linear Approximation and GMM Estimation." Revision 7: May 1.

Chari, V. V., Kehoe, P.J. and McGrattan, E. R. (2000): "Sticky Price Models of the Business Cycle: Can the Contract Multiplier Solve the Persistence Problem?" Econometrica 68: 1151-1179.

Cho, J.-O. and Cooley, Th. F. (1995): "The Business Cycle with Nominal Contracts.",Economic Theory 6: 13-33.

Christiano, L. J., Eichenbaum, M. and Evans, Ch. L. (1997): "Sticky Price and Limited Participation Models of Money: A Comparison." European Economic Review 41: 1201-1249.

Christiano, L. J., Eichenbaum, M. and Evans, Ch. L. (1999): Monetary Policy Shocks: What Have We Learned and to What End? In: J. B. Taylor and M. Woodford (Eds.), Handbook of Macroeconomics Volume 1A, Amsterdam: Elsevier, 65-148.

Cooley, Th. F. and Hansen, G. D. (1995): Money and the Business Cycle. In: Th. F. Cooley (Ed.), "Frontiers of Business Cycle Research." Princeton University Press, Princeton, NJ: 175-216.

Cooley, Th. F. and Hansen, G. D. (1998): "The Role of Monetary Shocks in Equilibrium Business Cycle Theory: Three Examples." European Economic Review 42: 605-617.

Einarsson, T. and Marquis, M. H. (1999): "Transitional and Steady-state Costs of Disinflation When Growth is Endogenous." Economica 66: 489-508.

Einarsson, T. and Marquis, M. H. (1997): "Home Production with Endogenous Growth." Journal of Monetary Economics 39: 551-569.

Feenstra, R. (1986): "Functional Equivalence Between Liquidity Costs and the Utility of Money." Journal of Monetary Economics 17: 271-291. 
Fischer, St. (1977): "Long-Term Contracts, Rational Expectations, and the Optimal Money Supply Rule." Journal of Political Economy 85: 191-205.

Friedman, M. (1969): The Optimal Quantity of Money and Other Essays., Chicago: Adline.

Giarini, O. and Liedtke, P. M. (1998): Wie wir arbeiten werden. Der neue Bericht an den Club of Rome. Hamburg: Hoffmann und Campe.

Gomme, P. (1993): "Money and Growth Revisited, Measuring the Costs of Inflation in an Endogenous Growth Model." Journal of Monetary Economics 31: 51-77.

King, R. G. and Watson, M. W. (2000): "System Reduction and Solution Algorithms for Singular Linear Difference Systems under Rational Expectations." Computational Economics 20: 57-86.

Hairault, J.-O. and Portier, F. (1993): "Money, New-Keynesian Macroeconomics and the Business Cycle." European Economic Review 37: 1533-1568.

Hoffman, D. L., Rasche, R. H. and Tieslau, M. A. (1995): "The Stability of Long-Run Money Demand in Five Industrial Countries." Journal of Monetary Economics 35: 317-339.

King, R. G., Plosser, Ch. I. and Rebelo, S. (1988): "Production, Growth and Business Cycles I, The Basic Neoclassical Model." Journal of Monetary Economics 21: 195-232.

Lucas, R. E. (1988): "On the Mechanics of Economic Development." Journal of Monetary Economics 22: 3-42.

Marimon, R. and Scott, A. (Eds.) (1999): "Computational Methods for the Study of Dynamic Economies." Oxford University Press. Oxford, New York.

Maussner, A. (2002): "Adjustment Costs and Nominal Rigidities in a Small Open Economy." Jahrbücher für Nationalökonomie und Statistik 463-489

Ozlu, E. (1996): "Aggregate Economic Fluctuations in Endogenous Growth Models." Journal of Macroeconomics 18: 27-47.

Rebelo, S. (1991): "Long-Run Policy Analysis and Long-Run Growth." Journal of Political Economy 99: 500-521.

Uzawa, H. (1965): "Optimal Technical Change in a Two-Sector Model of Capital Accumulation." International Economic Review 6: 18-31. 


\section{Appendix}

CES Index This paragraph considers a more general formulation for the labor index (1) used in the body of the paper. It demonstrates that this generalization does not change the log-linear version of the labor market clearing condition (14b).

Assume that the labor services $N_{i}^{c}, i=1,2, \ldots n$ of contract workers are aggregated by the following index:

$$
L^{c}=n^{\frac{1}{1-\sigma}}\left[\sum_{i=1}^{n}\left(N_{i}^{c}\right)^{\frac{\sigma-1}{\sigma}}\right]^{\frac{\sigma}{\sigma-1}},
$$

where $\sigma \in[0, \infty)$ is the elasticity of substitution between two groups of contract workers. Let $W_{i}^{c}$ denote the nominal wage (per efficiency unit) of labor of typ $i$. The representative firm chooses $N_{i}^{c}$ so as to minimize the wage bill of contract workers:

$$
\min W^{c} L^{c}:=\sum_{i=1}^{n} W_{i}^{c} N_{i}^{c} .
$$

This implies the following demand function for group $i$ :

$$
N_{i}^{c}=\left(W_{i}^{c} / W^{c}\right)^{-\sigma} \frac{L^{c}}{n}
$$

where

$$
W^{c}=\left[\frac{1}{n} \sum_{i=1}^{n}\left(W_{i}^{c}\right)^{1-\sigma}\right]^{\frac{1}{1-\sigma}}
$$

is the wage index for the group of contract workers.

Contract workers $N^{c}$ and labor hired from the spot market $N^{s}$ are combined to yield total labor input according to

$$
L=\left[\varphi^{1 / \sigma}\left(N^{c}\right)^{\frac{\sigma-1}{\sigma}}+(1-\varphi)^{1 / \sigma}\left(N^{s}\right)^{\frac{\sigma-1}{\sigma}}\right]^{\frac{\sigma}{\sigma-1}} .
$$

Let $W^{s}$ denote the nominal wage (per efficiency unit) of spot market workers. Minimization of labor costs

$$
W L:=W^{c} N^{c}+W^{s} N^{s}
$$

yields the demand functions for both types of labor and the corresponding wage index $W:$

$$
\begin{aligned}
& N^{c}=\varphi\left(W^{c} / W\right)^{-\sigma} L, \\
& N^{s}=(1-\varphi)\left(W^{s} / W\right)^{-\sigma} L, \\
& W=\left[\varphi\left(W^{c}\right)^{1-\sigma}+(1-\varphi)\left(W^{s}\right)^{1-\sigma}\right]^{\frac{1}{1-\sigma}} .
\end{aligned}
$$


Given these results, and the fact that both $W^{c}$ and $W$ are homogenous of degree one, the condition for labor market equilibrium (14b) may be rewritten as follows:

$$
\begin{aligned}
\alpha Z_{t} N_{t}^{\alpha-1} k_{t}^{1-\alpha} & =\left[\varphi\left(w_{t}^{c} / \pi_{t}\right)^{1-\sigma}+(1-\varphi)\left(W_{t}^{s} / P_{t}\right)^{1-\sigma}\right]^{\frac{1}{1-\sigma}}=(W / P)_{t}, \\
\frac{u_{3}\left(c_{t}, m_{t} / \pi_{t}, 1-N_{t}\right)}{\lambda_{t}} & =\left(W_{t}^{s} / P_{t}\right) .
\end{aligned}
$$

Since the labor market is competitive, the deterministic steady state of the model implies equal real wages for all kinds of workers: $W_{i}^{c} / P=W^{s} / P=W / P$. Using this, log-linearizing of the preceding equations at the stationary equilibrium gives:

$$
\begin{aligned}
\hat{Z}_{t}+(\alpha-1) \hat{N}_{t}+(1-\alpha) \hat{k}_{t} & =(1-\varphi) \widehat{W_{t}^{s} / P_{t}}+\varphi \hat{w}_{t}^{c}-\varphi \hat{\pi}_{t} \\
& =(1-\varphi) \widehat{\left(\frac{u_{3}(\cdot)}{\lambda_{t}}\right)}+\frac{\varphi}{n} \sum_{i=1}^{n} \hat{w}_{i t}^{c}-\varphi \hat{\pi}_{t}
\end{aligned}
$$

This is the same equation as the one derived from log-linearizing (14b).

If labor markets were monopolistically competitive, then, for $\sigma>1$, conditions (10b) and (10c) would change to:

$$
\begin{aligned}
\Lambda_{t} A_{t} \frac{\left(W_{t}^{s}\right)}{P_{t}} & =\frac{\sigma}{\sigma-1} u_{3}\left(C_{t}, M_{t} / P_{T}, 1-N_{t}\right) \\
0 & =E_{t}\left(\Lambda_{t+1} A_{t+1} \frac{W_{1 t+1}^{c}}{P_{t+1}}-\frac{\sigma}{\sigma-1} u_{3}\left(C_{t+1}, M_{t+1} / P_{t+1}, 1-N_{t+1}\right)\right) .
\end{aligned}
$$

The log-linearized labor market equilibrium condition would still be given by (A.1). However, the stationary version of this condition (using the parameterization of the current period utility in (9)) changes to

$$
\alpha \frac{y}{c} \frac{1-N}{N}\left[1+\frac{1-\gamma}{\gamma}\left(\frac{M / P}{C}\right)^{\nu}\right]^{-1}=\theta \frac{\sigma}{\sigma-1} .
$$

Thus, given $\sigma>1$ as well as $y / c, M /(P C)$, and $N$ the implied value of $\theta$ from this equation is smaller than in the competitive framework. This in turn implies a higher intertemporal elasticity of substitution with respect to leisure.

Dynamics of the Endogenous Growth Model The system of stochastic difference equations that determines the dynamics of the endogenous growth model is a simple adaptation and extension of the equations that characterize the benchmark model presented in equations (14). The household's first order condition with respect to consumption still holds:

$$
u_{1}\left(c_{t}, m_{t} / \pi_{t}, 1-N_{t}\right)=\lambda_{t}
$$


The analog to equation (14b) derived from the household's first order condition with respect to spot market labor supply $N_{t}^{s}$ and the definition of the wage index $(5 \mathrm{c})$ is

$$
\alpha Z_{Y t}\left(u_{t} N_{t}\right)^{\alpha-1}\left(v_{t} k_{t}\right)^{1-\alpha}=\left(\frac{u_{3}\left(c_{t}, m_{t} / \pi_{t}, 1-N_{t}\right)}{\lambda_{t}}\right)^{1-\varphi} \prod_{i=1}^{n}\left(\frac{w_{i t}^{c}}{\pi_{t}}\right)^{\varphi / n} .
$$

Since now the growth factor $a_{t}:=A_{t+1} / A_{t}$ is endogenous, equation (14c) must be rewritten as:

$$
m_{t+1}=\frac{g_{t}}{a_{t} \pi_{t}} m_{t}
$$

There are three additional equations that determine the three additional variables $q_{t}$, $u_{t}$, and $v_{t}$. These equations are (21c), (21d), and the production function of sector 2 , which can be written in stationary variables after division by $A_{t}$. Thus:

$$
\begin{aligned}
q_{t} & =\frac{\alpha Z_{Y t}\left(u_{t} L_{t}\right)^{\alpha-1}\left(v_{t} k_{t}\right)^{1-\alpha}}{\zeta Z_{A t}\left[\left(1-u_{t}\right) L_{t}\right]^{\zeta-1}\left[\left(1-v_{t}\right) k_{t}\right]^{1-\zeta}}, \\
\frac{v_{t}}{1-v_{t}} & =\frac{1-\alpha}{\alpha} \frac{\zeta}{1-\zeta} \frac{u_{t}}{1-u_{t}}, \\
a_{t}-\left(1-\delta_{A}\right) & =Z_{A t}\left[\left(1-u_{t}\right) L_{t}\right]^{\zeta}\left[\left(1-v_{t}\right) k_{t}\right]^{1-\zeta} .
\end{aligned}
$$

Since the factor payments of sector 2 are equal to this sector's output in terms of sector 1 goods, $q_{t}\left(A_{t+1}-\left(1-\delta_{A}\right) A_{t}\right)$, the household's budget constraint (16) reduces to

$$
a_{t} k_{t+1}=Z_{Y t}\left(u_{t} L_{t}\right)^{\alpha}\left(v_{t} k_{t}\right)^{1-\alpha}+\left(1-\delta_{K}\right) k_{t}-c_{t} .
$$

The household's Euler equation with respect to physical capital accumulation, equation (14e) is modified to

$$
\lambda_{t}=\beta a_{t}{ }^{-\eta} E_{t} \lambda_{t+1}\left(1-\delta_{K}+(1-\alpha) Z_{Y t+1}\left(u_{t+1} N_{t+1}\right)^{\alpha}\left(v_{t+1} k_{t+1}\right)^{-\alpha}\right) .
$$

Using (21a), the Euler equation with respect to human capital accumulation (17) can be written as:

$$
\lambda_{t} q_{t}=\beta a_{t}{ }^{-\eta} E_{t} \lambda_{t+1}\left(Z_{Y t+1}\left(u_{t+1} L_{t+1}\right)^{\alpha-1}\left(v_{t+1} k_{t+1}\right)^{1-\alpha} L_{t+1}-q_{t+1}\left(1-\delta_{A}\right)\right)
$$

In the Euler equation for money accumulation $a$ must be replaced by $a_{t}$, but it remains otherwise unchanged:

$$
\lambda_{t}=\beta a_{t}^{-\eta} E_{t}\left(\frac{u_{2}\left(c_{t+1}, m_{t+1} / \pi_{t+1}, 1-N_{t+1}\right)+\lambda_{t+1}}{\pi_{t+1}}\right) .
$$

Since $a_{t}$ and hence $A_{t+1}$ are determined in period $t$, the first order condition with respect to the new contract wage, equation (10c), is still equivalent to equation $(14 \mathrm{~g})$, 
which I reproduce here together with the unchanged equations for the dynamics of the wage index:

$$
\begin{aligned}
0 & =E_{t}\left(\lambda_{t+1} \frac{w_{1 t+1}^{c}}{\pi_{t+1}}-u_{3}\left(c_{t+1}, m_{t+1} / \pi_{t+1}, 1-N_{t+1}\right)\right), \\
w_{i+1 t+1}^{c} & =\frac{\pi}{\pi_{t}} w_{i t}^{c}, \quad i=1,2, \ldots, n-1 .
\end{aligned}
$$

Balanced Growth The balanced growth path of the deterministic counterpart to the model presented in equations (A.2) is found by dropping time indices and the expectations operator in (A.2). I use the parameterization of the utility function given in equation (9) to derive the conditions that hold along that path.

Considering (A.2c) it is immediate that the long run rate of inflation is

$$
\pi=g / a
$$

Using this result and the parameterization of the utility function, equation (A.2j) and (A.2a) imply the long run velocity of money with respect to consumption:

$$
\frac{C}{M / P}=\left[\frac{\gamma}{1-\gamma} \frac{g a^{\eta-1}-\beta}{\beta}\right]^{1 /(1-\nu)} .
$$

Since $\nu<1$, the velocity of money is an increasing function of the growth rate of money $g$. Without shocks spot and contract market workers earn the same wage and $N=L$. Thus, equation (A.2b) reduces to

$$
W / P=\alpha Z_{Y}(u N / v k)^{\alpha-1}=\frac{u_{3}(c, M /(A P), 1-N)}{u_{1}(c, M /(A P), 1-N)} .
$$

Together with (A.4) this gives:

$$
\begin{aligned}
\frac{W}{P} & =\alpha Z_{Y}\left(\frac{u N}{v k}\right)^{(\alpha-1)}=\theta \frac{c}{1-N} \Delta(g), \\
\Delta(g) & =1+\frac{1-\gamma}{\gamma}\left(\frac{\gamma}{1-\gamma} \frac{g a^{\eta-1}-\beta}{\beta}\right)^{\nu /(\nu-1)} .
\end{aligned}
$$

Without money, i.e., if $\gamma=1$, the term $\Delta(g)$ reduces to 1 . In the case of log-linear preferences and a cash in advance constraint, the case considered by Gomme (1993) and Einarsson and Marquis (1998), i.e., if $\eta=1$ and $\nu \rightarrow-\infty$, this function simplifies to $\Delta(g)=g / \beta$. It gives the wedge between the marginal product of labor and the marginal rate of substitution between leisure and consumption introduced by money holdings. In the loglinear, cash in advance model, this wedge is independent of the growth rate of output, but an increasing (decreasing) function of the growth rate of output for $\eta>1(\eta<1)$. This introduces the ambiguity in the relationship between money and output growth referred to in the body of the paper. 
The remaining equations that are necessary to determine the models variables on the balanced growth path are simply equations (A.2d) to (A.2i) without the time indices and the expectations operator and with $L$ replaced by $N$, i.e.,

$$
\begin{aligned}
q & =\frac{\alpha Z_{Y}(u N / v k)^{\alpha-1}}{\zeta Z_{A}[(1-u) N /(1-v) k]^{\zeta-1},} \\
\frac{v}{1-v} & =\frac{1-\alpha}{\alpha} \frac{\zeta}{1-\zeta} \frac{u}{1-u}, \\
a+\delta_{A}-1 & =Z_{A}[(1-u) N]^{\zeta}[(1-v) k]^{1-\zeta}, \\
\left(a+\delta_{K}-1\right) k & =Z_{Y}(u N)^{\alpha}(v k)^{1-\alpha}-c, \\
\frac{a^{\eta}}{\beta} & =1-\delta_{K}+(1-\alpha) Z_{Y}(u N / v k)^{\alpha}, \\
q\left(1-\delta_{A}+\frac{a^{\eta}}{\beta}\right) & =Z_{Y}(u N / v k)^{\alpha-1} N .
\end{aligned}
$$

The seven equations (A.5) determine $u, v, N, k, c, q$ and $a$, given the parameters of the model.

Details of the Calibration Assume that $\beta, \delta_{A}, \delta_{K}, \eta, \nu$, and $\zeta$ have been determined and that $a, g, N$, and $C /(M / P)$ shall be chosen to match their respective empirical values. With $Z_{Y}$ normalized to one, the steady state equations determine the values of the remaining parameters.

Equation (A.4) can be solved for $\gamma$, and equations (A.5b), (A.5c), (A.5d), (A.5f) and $(\mathrm{A} .5 \mathrm{~g})$ reduce to

$$
u=\frac{a^{\eta}-\beta\left(1-\delta_{A}\right)+\beta \zeta\left(1-a-\delta_{A}\right)}{a^{\eta}-\beta\left(1-\delta_{A}\right)} .
$$

Labor's share in GDP, say $\omega$, is given by

$$
\omega:=\frac{(W / P) N}{y+q\left(a+\delta_{A}-1\right)} .
$$

Using the steady state version of (21a) together with (A.5b) and (A.5d) this definition implies:

$$
\omega=\frac{\alpha \zeta}{\zeta u+\alpha(1-u)} .
$$

Given $\omega$ and $u$, equation (A.7) pins down the value of $\alpha$.

Via equation (A.5c) $v$ is known, once $u$ is determined. With $N$ given, I use $u N$ to compute $v k$ from equation (A.5f). Now, $k$ is also known and equation (A.5e) gives $c$, so that $\theta$ follows from the labor market equilibrium condition (A.5a). Finally, equation (A.5d) implies the value of $Z_{A}$. 
The Log-Linearized Model Let variables with a hat denote percentage deviations from a variable's steady state level, i.e.,

$$
\hat{x}_{t}:=\frac{x_{t}-x}{x} .
$$

Using the parameterization of the households preferences given in defintion (9), the log-linearized equations (A.2) read:

$$
\begin{aligned}
& 0=b_{11} \hat{c}_{t}-b_{12} \hat{N}_{t}-b_{13} \hat{\pi}_{t}+b_{13} d_{2} \hat{m}_{t}+\hat{\lambda}_{t}, \\
& b_{11}:=\nu-1+(1-\eta-\nu) d_{1}, \\
& b_{12}:=\theta(1-\eta) \frac{N}{1-N} \text {, } \\
& b_{13}:=(1-\eta-\nu) d_{2} \text {, } \\
& d_{1}:=\frac{1}{1+((1-\gamma) / \gamma)(M / P C)^{\nu}}, \quad d_{2}=\frac{1}{1+(\gamma /(1-\gamma))(P C / M)^{\nu}} \\
& 0=b_{21} \hat{c}_{t}+b_{22} \hat{N}_{t}+b_{23} \hat{u}_{t}-b_{24} \hat{\pi}_{t}-(1-\alpha) \hat{k}_{t}+b_{25} \hat{m}_{t}+\sum_{i=1}^{n}(\varphi / n) \hat{w}_{i t}^{c} \\
& -(1-\varphi) \hat{\lambda}_{t}-\hat{Z}_{Y t} \\
& b_{21}:=(1-\varphi)(1-\eta) d_{1}, \\
& b_{22}=1+\alpha+(1-\varphi)[\theta(1-\eta)-1] \frac{N}{1-N}, \\
& b_{23}:=(1-\alpha) \frac{v-u}{1-u}, \\
& b_{24}:=\varphi+(1-\varphi)(1-\eta) d_{2}, \\
& b_{25}:=(1-\varphi)(1-\eta) d_{2} \\
& 0=b_{31} \hat{N}_{t}-b_{32} \hat{u}_{t}+b_{33} \hat{k}_{t}-\hat{a}_{t}+\frac{a+\delta_{A}-1}{a} \hat{Z}_{A t}, \\
& b_{31}:=\frac{\zeta\left(a+\delta_{A}-1\right)}{a}, \\
& b_{32}:=\left[\frac{a+\delta_{a}-1}{a}\right]\left[\frac{\zeta u+(1-\zeta) v}{1-u},\right] \\
& b_{33}:=(1-\zeta) \frac{a+\delta_{a}-1}{a} \\
& 0=b_{41} \hat{u}_{t}+\hat{q}_{t}+(\zeta-\alpha) \hat{N}_{t}-(\zeta-\alpha) \hat{k}_{t}-\hat{Z}_{Y t}+\hat{Z}_{A t}, \\
& b_{41}:=\frac{(\alpha-\zeta)(u-v)}{1-u}
\end{aligned}
$$




$$
0=\hat{\pi}_{t}-\hat{m}_{t}+\hat{m}_{t+1}+\hat{a}_{t}-\hat{g}_{t}
$$

$$
0=a \hat{k}_{t+1}+a \hat{a}_{t}-b_{61} \hat{k}_{t}+(c / k) \hat{c}_{t}-\alpha(y / k) \hat{N}_{t}-b_{62} \hat{u}_{t}-(y / k) \hat{Z}_{Y t},
$$

$$
\begin{aligned}
b_{61} & :=(1-\alpha)(y / k)+1-\delta_{K}, \\
b_{62} & :=\alpha+(1-\alpha) \frac{1-v}{1-u},
\end{aligned}
$$

$$
\begin{aligned}
0 & =\alpha b_{71} \hat{k}_{t+1}-E_{t} \hat{\lambda}_{t+1}+\hat{\lambda}_{t}+\eta \hat{a}_{t}-\alpha b_{71} E_{t} \hat{N}_{t+1}-\alpha b_{72} E_{t} \hat{u}_{t+1} \\
& -b_{71} E_{t} \hat{Z}_{Y t+1}
\end{aligned}
$$

$$
\begin{aligned}
b_{71} & :=1-\beta a^{-\eta}\left(1-\delta_{K}\right), \\
b_{72} & :=\alpha b_{71} \frac{v-u}{1-u}, \\
0 & =(1-\alpha) b_{81} \hat{k}_{t+1}+E_{t} \hat{\lambda}_{t+1}-\hat{\lambda}_{t}-\eta \hat{a}_{t}+\alpha b_{81} E_{t} \hat{N}_{t+1} \\
& -(1-\alpha) \frac{v-u}{1-u} b_{81} E_{t} \hat{u}_{t+1}+\left(1-\delta_{A}\right) \beta a^{-\eta} E_{t} \hat{q}_{t+1}-\hat{q}_{t}+b_{81} E_{t} \hat{Z}_{Y t+1},
\end{aligned}
$$

$$
\begin{aligned}
b_{81} & :=1-\beta a^{-\eta}\left(1-\delta_{A}\right) \\
0 & =E_{t} \hat{\lambda}_{t+1}-\hat{\lambda}_{t}-\eta \hat{a}_{t}-b_{91} \hat{m}_{t+1}+b_{91} E_{t} \hat{c}_{t+1}-b_{92} E_{t} \hat{\pi}_{t+1}, \\
b_{91} & :=(1-\nu)\left(1-\frac{\beta a^{1-\eta}}{g}\right) \\
b_{92}:=\nu+(1-\nu) \frac{\beta a^{1-\eta}}{g}, & \\
0 & =E_{t} \hat{w}_{1 t+1}^{c}+E_{t} \hat{\lambda}_{t+1}-(1-\eta) d_{2} \hat{m}_{t+1}-(1-\eta) d_{1} E_{t} \hat{c}_{t+1} \\
& +b_{101} E_{t} \hat{N}_{t+1}-\left(1-(1-\eta) d_{2}\right) E_{t} \hat{\pi}_{t+1}, \\
b_{101} & =(1-\theta(1-\eta)) \frac{N}{1-N}, \\
0= & E_{t} \hat{w}_{i+1}^{c}{ }_{t+1}-\hat{w}_{i t}^{c}+\hat{\pi}_{t}, \quad i=1,2, \ldots, n-1,
\end{aligned}
$$

where I used

$$
\hat{v}=\frac{1-v}{1-u} \hat{u}_{t}
$$

from (A.2e) and $\hat{N}_{t}=\hat{L}_{t}$, which is implied by the definition of the labor index (1) and by the labor demand equations (5) to simplify the exposition. 
Sensitivity Analysis Table A. 1 demonstrates that in the log-linearized version of the exogenous growth model with with preferences that are linear in the logs of consumption, real money balances, and leisure, money is neutral with respect to the real variables if there are no nominal frictions present.

Table A. 1

Stable Money Growth in the Exogenous Growth Model

Loglinear Preferences without Nominal Frictions: $\eta=1, \nu=\varphi=0$

\begin{tabular}{lcrr}
\hline \hline Variable & \multicolumn{2}{c}{$s_{x}$} & $\Delta s_{x}$ \\
& $\sigma_{g}=1.0172$ & $\sigma_{g}=0$ & \\
\hline Output & 1.56 & 1.56 & 0.00 \\
Consumption & 0.32 & 0.32 & 0.00 \\
Investment & 6.27 & 6.27 & 0.00 \\
Hours & 0.94 & 0.94 & 0.00 \\
Real Wage & 0.64 & 0.64 & 0.00 \\
Inflation & 1.67 & 0.20 & -87.74 \\
Real Money Balances & 0.32 & 0.32 & 0.00 \\
\hline
\end{tabular}

Notes:

$s_{x}:=$ Standard deviation of variable $x, \Delta s_{x}:=$ percentage change of standard deviation of variable $x$ relative to the case of constant money growth. 
Table A. 2 together with Table 2 reveals the role of the intertemporal elasticity of substitution with respect to consumption $\eta$. The second moments displayed in this table are from a simulation with unit elasticity. In this case, the intertemporal elasticity of substitution with respect to leisure is unity, too.

Table A. 2

Selected Moments from the Exogenous Growth Model

$$
\eta=1
$$

\begin{tabular}{lccccc}
\hline \hline Variable & $s_{x}$ & $s_{x y}$ & $r_{x}$ & $r_{x y}$ & $r_{x m}$ \\
\hline Output & 1.84 & 1.00 & 0.60 & 1.00 & 0.78 \\
& $(1.24)$ & $(1.00)$ & $(0.79)$ & $(1.00)$ & $(0.35)$ \\
Consumption & 0.37 & 0.20 & 0.59 & 0.53 & 0.86 \\
& $(1.10)$ & $(0.88)$ & $(0.82)$ & $(0.66)$ & $(0.57)$ \\
Investment & 7.87 & 4.27 & 0.56 & 0.99 & 0.70 \\
Hours & $(2.54)$ & $(2.04)$ & $(0.81)$ & $(0.81)$ & $(0.44)$ \\
& 1.64 & 0.89 & 0.54 & 0.92 & 0.56 \\
Real Wage & $(0.84)$ & $(0.68)$ & $(0.42)$ & $(0.30)$ & $(-0.23)$ \\
& 0.74 & 0.40 & 0.64 & 0.44 & 0.70 \\
Inflation & $(1.06)$ & $(0.85)$ & $(0.52)$ & $(0.37)$ & $(0.18)$ \\
& 1.63 & 0.90 & -0.10 & 0.24 & 0.02 \\
Real Money Balances & $(0.28)$ & $(0.23)$ & $(-0.03)$ & $(0.13)$ & $(-0.19)$ \\
& $(2.58)$ & 0.18 & 0.76 & 0.78 & 1.00 \\
& & $(2.08)$ & $(0.80)$ & $(0.35)$ & $(1.00)$ \\
\hline
\end{tabular}

Notes:

$s_{x}:=$ Standard deviation of variable $x, s_{x y}:=$ standard deviation of variable $x$ relative to the standard deviation of output, $r_{x}:=$ first order autocorrelation of variable $x, r_{x y}:=$ first order cross correlation of variable $x$ with output, $r_{x m}:=$ first order cross correlation of variable $x$ with real money balances;

Simulated moments are averages of 500 simulations of HP-filtered series with 60 observations each.

Empirical values from HP-filtered data from 75.i to 89.iv in parentheses. 
Table A. 3 presents the results of a simulation of the benchmark model using the parameter values of the US M1 growth rate taken from CoOLEY and HANsEN (1995), p. 201. All other parameters are the same as those given in Table 1.

Table A. 3

Selected Moments from the Exogenous Growth Model

$$
g=1.013, \rho_{g}=0.49, \sigma_{g}=0.0089
$$

\begin{tabular}{lccccc}
\hline \hline Variable & $s_{x}$ & $s_{x y}$ & $r_{x}$ & $r_{x y}$ & $r_{x m}$ \\
\hline Output & 1.51 & 1.00 & 0.61 & 1.00 & 0.10 \\
& $(1.24)$ & $(1.00)$ & $(0.79)$ & $(1.00)$ & $(0.35)$ \\
Consumption & 0.58 & 0.38 & 0.60 & 0.99 & 0.03 \\
& $(1.10)$ & $(0.88)$ & $(0.82)$ & $(0.66)$ & $(0.57)$ \\
Investment & 5.11 & 3.37 & 0.61 & 1.00 & 0.12 \\
& $(2.54)$ & $(2.04)$ & $(0.81)$ & $(0.81)$ & $(0.44)$ \\
Hours & 1.05 & 0.70 & 0.55 & 0.89 & -0.33 \\
& $(0.84)$ & $(0.68)$ & $(0.42)$ & $(0.30)$ & $(-0.23)$ \\
Real Wage & 0.74 & 0.49 & 0.66 & 0.76 & 0.67 \\
& $(1.06)$ & $(0.85)$ & $(0.52)$ & $(0.37)$ & $(0.18)$ \\
Inflation & 1.49 & 1.01 & -0.05 & 0.16 & -0.84 \\
& $(0.28)$ & $(0.23)$ & $(-0.03)$ & $(0.13)$ & $(-0.19)$ \\
Real Money Balances & 0.73 & 0.49 & 0.39 & 0.10 & 1.00 \\
& $(2.58)$ & $(2.08)$ & $(0.80)$ & $(0.35)$ & $(1.00)$ \\
\hline
\end{tabular}

Notes:

$s_{x}:=$ Standard deviation of variable $x, s_{x y}:=$ standard deviation of variable $x$ relative to the standard deviation of output, $r_{x}:=$ first order autocorrelation of variable $x, r_{x y}:=$ first order cross correlation of variable $x$ with output, $r_{x m}:=$ first order cross correlation of variable $x$ with real money balances;

Simulated moments are averages of 500 simulations of HP-filtered series with 60 observations each.

Empirical values from HP-filtered data from 75.i to 89.iv in parentheses. 
Table A. 4 presents second moments from the endogenous growth model using the same money supply process underlying Table A. 3.

Table A. 4

Selected Moments from the Endogenous Growth Model

$$
g=1.013, r h o_{g}=0.49, \sigma_{g}=0.0089
$$

\begin{tabular}{lccccc}
\hline \hline Variable & $s_{x}$ & $s_{x y}$ & $r_{x}$ & $r_{x y}$ & $r_{x m}$ \\
\hline GDP & 1.23 & 1.00 & 0.60 & 1.00 & 0.00 \\
& $(1.24)$ & $(1.00)$ & $(0.79)$ & $(1.00)$ & $(0.35)$ \\
Sector 1 Output & 1.98 & 1.64 & 0.64 & 0.25 & 0.11 \\
Sector 2 Output & 3.89 & 3.22 & 0.59 & 0.61 & -0.09 \\
Sector 1 Investment & 6.20 & 5.16 & 0.62 & -0.02 & 0.16 \\
Aggregate Investment & 1.53 & 1.25 & 0.62 & 0.99 & 0.08 \\
& $(2.54)$ & $(2.04)$ & $(0.81)$ & $(0.81)$ & $(0.44)$ \\
Consumption & 0.89 & 0.73 & 0.58 & 0.91 & -0.19 \\
& $(1.10)$ & $(0.88)$ & $(0.82)$ & $(0.66)$ & $(0.57)$ \\
Sector 1 Hours & 2.24 & 1.86 & 0.63 & -0.07 & -0.05 \\
Sector 2 Hours & 3.29 & 2.73 & 0.57 & 0.52 & -0.20 \\
Aggregate Hours & 1.10 & 0.91 & 0.52 & 0.79 & -0.37 \\
& $(0.84)$ & $(0.68)$ & $(0.42)$ & $(0.30)$ & $(-0.23)$ \\
Real Wage & 0.82 & 0.67 & 0.67 & 0.80 & 0.40 \\
& $(1.06)$ & $(0.85)$ & $(0.52)$ & $(0.37)$ & $(0.18)$ \\
Inflation & 1.48 & 1.23 & -0.03 & 0.26 & -0.83 \\
& $(0.28)$ & $(0.23)$ & $(-0.03)$ & $(0.13)$ & $(-0.19)$ \\
Real Money Balances & 0.72 & 0.60 & 0.41 & 0.00 & 1.00 \\
& $(2.58)$ & $(2.08)$ & $(0.80)$ & $(0.35)$ & $(1.00)$ \\
\hline
\end{tabular}

Notes:

$s_{x}:=$ Standard deviation of variable $x, s_{x y}:=$ standard deviation of variable $x$ relative to the standard deviation of output $r_{x}:=$ first order autocorrelation of variable $x, r_{x y}:=$ first order cross correlation of variable $x$ with GDP, $r_{x m}:=$ first order cross correlation of variable $x$ with real money balances;

Simulated moments are averages of 500 simulations of HP-filtered series with 60 observations each.

Empirical values from HP-filtered data from $75 . \mathrm{i}$ to 89 .iv in parentheses. 
Tables A. 5 and A. 6 present selected moments from simulations of the endogenous growth model for two different values of $\zeta$.

Table A. 5

Selected Moments from the Endogenous Growth Model

$$
\zeta=1 \text { and } \sigma_{A}=0.94 \sigma_{Z}
$$

\begin{tabular}{lccccc}
\hline \hline Variable & $s_{x}$ & $s_{x y}$ & $r_{x}$ & $r_{x y}$ & $r_{x m}$ \\
\hline GDP & 1.24 & 1.00 & 0.60 & 1.00 & 0.91 \\
& $(1.24)$ & $(1.00)$ & $(0.79)$ & $(1.00)$ & $(0.35)$ \\
Sector 1 Output & 1.61 & 1.32 & 0.64 & 0.37 & 0.25 \\
Sector 2 Output & 3.28 & 2.68 & 0.59 & 0.68 & 0.68 \\
Sector 1 Investment & 4.94 & 4.07 & 0.62 & 0.03 & -0.04 \\
Aggregate Investment & 1.54 & 1.25 & 0.61 & 0.99 & 0.91 \\
& $(2.54)$ & $(2.04)$ & $(0.81)$ & $(0.81)$ & $(0.44)$ \\
Consumption & 0.89 & 0.73 & 0.59 & 0.92 & 0.81 \\
& $(1.10)$ & $(0.88)$ & $(0.82)$ & $(0.66)$ & $(0.57)$ \\
Sector 1 Hours & 1.79 & 1.47 & 0.64 & -0.03 & -0.18 \\
Sector 2 Hours & 2.70 & 2.21 & 0.57 & 0.59 & 0.56 \\
Aggregate Hours & 1.12 & 0.91 & 0.53 & 0.81 & 0.66 \\
& $(0.84)$ & $(0.68)$ & $(0.42)$ & $(0.30)$ & $(-0.23)$ \\
Real Wage & 0.81 & 0.65 & 0.66 & 0.80 & 0.92 \\
& $(1.06)$ & $(0.85)$ & $(0.52)$ & $(0.37)$ & $(0.18)$ \\
Inflation & 1.61 & 1.33 & -0.07 & 0.27 & 0.14 \\
& $(0.28)$ & $(0.23)$ & $(-0.03)$ & $(0.13)$ & $(-0.19)$ \\
Real Money Balances & 0.34 & 0.27 & 0.65 & 0.91 & 1.00 \\
& $(2.58)$ & $(2.08)$ & $(0.80)$ & $(0.35)$ & $(1.00)$ \\
\hline
\end{tabular}

\section{Notes:}

$s_{x}:=$ Standard deviation of variable $x, s_{x y}:=$ standard deviation of variable $x$ relative to the standard deviation of output $r_{x}:=$ first order autocorrelation of variable $x, r_{x y}:=$ first order cross correlation of variable $x$ with GDP, $r_{x m}:=$ first order cross correlation of variable $x$ with real money balances;

Simulated moments are averages of 500 simulations of HP-filtered series with 60 observations each.

Empirical values from HP-filtered data from 75.i to 89.iv in parentheses. 
Table A. 6

Selected Moments from the Endogenous Growth Model

$$
\zeta=0.9 \text { and } \sigma_{A}=0.94 \sigma_{Z}
$$

\begin{tabular}{lccccc}
\hline \hline Variable & $s_{x}$ & $s_{x y}$ & $r_{x}$ & $r_{x y}$ & $r_{x m}$ \\
\hline GDP & 1.25 & 1.00 & 0.62 & 1.00 & 0.90 \\
& $(1.24)$ & $(1.00)$ & $(0.79)$ & $(1.00)$ & $(0.35)$ \\
Sector 1 Output & 2.58 & 2.09 & 0.64 & 0.13 & 0.18 \\
Sector 2 Output & 4.91 & 3.98 & 0.59 & 0.54 & 0.44 \\
Sector 1 Investment & 8.11 & 6.61 & 0.61 & -0.08 & -0.01 \\
Aggregate Investment & 1.55 & 1.24 & 0.62 & 0.98 & 0.91 \\
& $(2.54)$ & $(2.04)$ & $(0.81)$ & $(0.81)$ & $(0.44)$ \\
Consumption & 0.94 & 0.76 & 0.61 & 0.91 & 0.78 \\
& $(1.10)$ & $(0.88)$ & $(0.82)$ & $(0.66)$ & $(0.57)$ \\
Sector 1 Hours & 2.92 & 2.38 & 0.63 & -0.11 & -0.08 \\
Sector 2 Hours & 4.30 & 3.49 & 0.58 & 0.47 & 0.34 \\
Aggregate Hours & 1.16 & 0.94 & 0.52 & 0.77 & 0.55 \\
& $(0.84)$ & $(0.68)$ & $(0.42)$ & $(0.30)$ & $(-0.23)$ \\
Real Wage & 0.86 & 0.69 & 0.68 & 0.78 & 0.84 \\
& $(1.06)$ & $(0.85)$ & $(0.52)$ & $(0.37)$ & $(0.18)$ \\
Inflation & 1.61 & 1.32 & -0.07 & 0.27 & 0.14 \\
& $(0.28)$ & $(0.23)$ & $(-0.03)$ & $(0.13)$ & $(-0.19)$ \\
Real Money Balances & 0.33 & 0.27 & 0.70 & 0.90 & 1.00 \\
& $(2.58)$ & $(2.08)$ & $(0.80)$ & $(0.35)$ & $(1.00)$ \\
\hline
\end{tabular}

Notes:

$s_{x}:=$ Standard deviation of variable $x, s_{x y}:=$ standard deviation of variable $x$ relative to the standard deviation of output $r_{x}:=$ first order autocorrelation of variable $x, r_{x y}:=$ first order cross correlation of variable $x$ with GDP, $r_{x m}:=$ first order cross correlation of variable $x$ with real money balances;

Simulated moments are averages of 500 simulations of HP-filtered series with 60 observations each.

Empirical values from HP-filtered data from 75.i to 89.iv in parentheses. 
Finally, A. 7 presents the results of a simulation with log-linear preferences in consumption, real money balances, and leisure. It contrasts the effects of monetary policy for the growth and no-growth case.

Table A. 7

Stable Money Growth in the Endogenous Growth Model

Loglinear Preferences: $\eta=1$ and $\nu=0$

\begin{tabular}{lcrrrrr}
\hline \hline Variable & \multicolumn{3}{c}{$\begin{array}{c}c-1=0.005 \\
s_{x}\end{array}$} & \multicolumn{4}{c}{$a-1=0$} \\
& $\sigma_{g}=1.0172$ & $\sigma_{g}=0$ & & $\sigma_{g}=1.0172$ & $\sigma_{g}=0$ & $\Delta s_{x}$ \\
\hline GDP & 3.14 & 2.55 & -18.80 & 2.99 & 2.42 & -18.95 \\
Sector 1 Output & 2.26 & 2.25 & -0.60 & 2.23 & 2.22 & -0.45 \\
Sector 2 Output & 9.97 & 8.53 & -14.45 & 12.88 & 11.11 & -13.75 \\
Sector 1 Investment & 6.42 & 6.37 & -0.74 & 7.62 & 7.58 & -0.55 \\
Aggregate Investment & 5.21 & 4.22 & -19.09 & 5.97 & 4.82 & -19.32 \\
Consumption & 0.50 & 0.49 & -3.10 & 0.43 & 0.41 & -2.90 \\
Sector 1 Hours & 2.76 & 2.75 & -0.30 & 2.77 & 2.76 & -0.22 \\
Sector 2 Hours & 9.24 & 7.66 & -17.17 & 12.12 & 10.21 & -15.73 \\
Aggregate Hours & 4.20 & 3.17 & -24.45 & 4.33 & 3.28 & -24.07 \\
Real Wage & 0.99 & 0.98 & -0.56 & 0.99 & 0.99 & -0.33 \\
Inflation & 1.65 & 0.15 & -91.09 & 1.65 & 0.12 & -92.47 \\
Real Money Balances & 0.26 & 0.26 & -0.18 & 0.22 & 0.22 & -0.22 \\
\hline
\end{tabular}

Notes:

$s_{x}:=$ Standard deviation of variable $x, \Delta s_{x}:=$ percentage change of standard deviation of variable $x$ relative to the case of constant money growth.

Monetary Shocks in the Home Production Model The home production interpretation of the endogenous growth model requires different choices for some of the parameters. Since output and wage income of the economy are now identical to the market sector's production and wage bill, $\alpha$ equals labor's share of 0.66. Observed hours of work 0.28 are now identical to $u N$ from the model. In the endogenous growth framework sector 1 output is much more volatile than in the exogenous growth model, since in addition to intertemporal substitution there is also substitution of resources between the sectors. Thus, if the variance of the Solow residual is used to measure the size of shocks to the market sector's production function, the implied standard deviation of output is implausibly large. To arrive at plausibel results, I set $\sigma_{A}=\sigma_{Y}$ and reduced the size of the $\sigma_{Y}$ so that the variability of sector 1 output from the model matches that of West German GDP (net of government consumption). This requires $\sigma_{Y}=0031$.

Table A. 8 displays the standard deviation of selected variables that result from this calibration. It supports the claim that the home production sector almost insulates 
the market sector from the consequences of monetary shocks. For practical purposes, the standard deviations of sector 1 output and hours, as well as those of the real wage and of real money balances are virtually unchanged if a policy of constant money growth is adopted. Investment in physical capital becomes slightly less variable. Only consumption is markedly smoothed.

Table A. 8

Stable Money Growth in the Home Production Model

\begin{tabular}{lcrr}
\hline \hline Variable & \multicolumn{2}{c}{$s_{x}$} & $\Delta s_{x}$ \\
& $\sigma_{g}=1.0172$ & $\sigma_{g}=0$ & \\
\hline Sector 1 Output & 1.24 & 1.24 & -0.04 \\
Sector 2 Output & 1.65 & 1.48 & -10.00 \\
Sector 1 Investment & 5.33 & 5.21 & -2.34 \\
Consumption & 0.38 & 0.22 & -40.55 \\
Sector 1 Hours & 1.33 & 1.33 & -0.01 \\
Sector 2 Hours & 1.47 & 1.28 & -13.19 \\
Real Wage & 0.35 & 0.34 & -0.37 \\
Inflation & 1.62 & 0.08 & -94.86 \\
Real Money Balances & 0.14 & 0.14 & -3.80 \\
\hline & \multicolumn{4}{c}{} \\
Notes: & $s_{x}:=$ Standard deviation of variable $x, \Delta s_{x}:=$ percentage \\
change of standard deviation of variable $x$ relative to the case of \\
constant money growth.
\end{tabular}

